\title{
THE IMPACT OF ENABLING SKILLS ON EARLY READING ACQUISITION
}

Ieva Sprugevica

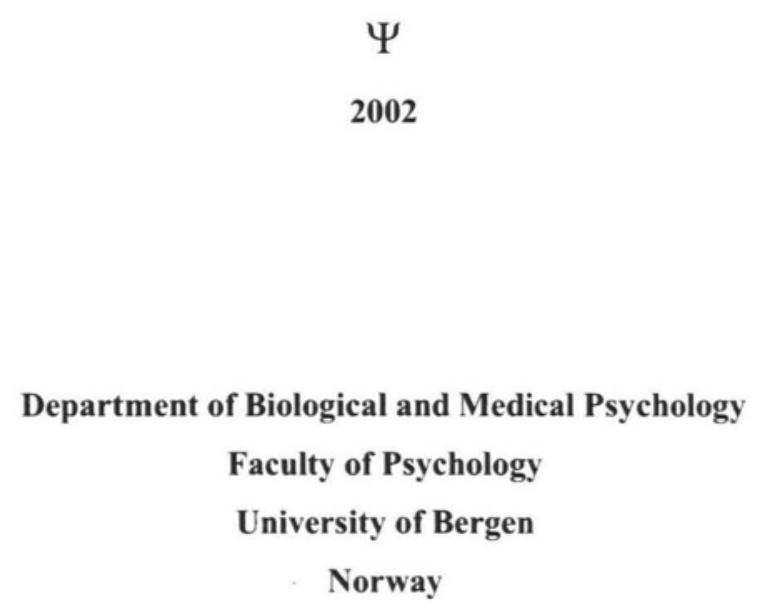


ISBN: 82-497-0163-1

University of Bergen

Norway 2003

Printed by Allkopi, Bergen - ph. +47 55544940 
CONTENTS

\section{ACKNOWLEDGMENTS:}

EMPIRICAL REPORTS:

ABSTRACT:

INTRODUCTION:

- Reading acquisition

- Enabling skills and early reading acquisition

- Phonological awareness

- Rapid naming

- Short-term memory

- Letter knowledge

HYPOTHESES AND RESEARCH QUESTIONS:

COMMON METHODS AND DESIGNS:

SUMMARY OF THE EMPIRICAL REPORTS:

- Report I

- Report II

- $\quad$ Report III

OVERALL DISCUSSION AND CONCLUSIONS:

REFERENCES:

EMPIRICAL REPORTS:

- Report I

- Report II

- Report III 


\section{ACKNOWLEDGMENTS:}

The research presented in this thesis was carried out at the Department of Psychology, University of Latvia. I wish to thank the Faculty of Psychology, University of Bergen, for giving me a Ph.D. scholarship and the Dyslexia Research Foundation and the Research Council of Norway for economically supporting the scientific research project and thereby giving me the opportunity to fulfil this work.

My deepest gratitude goes to my supervisor, Professor Torleiv Høien, for his professional supervision and excellent support during this work. I can say without exaggeration that without his supportive and empathic attitude this dissertation would not have been carried out.

I am also very grateful to friends and colleagues at the Dyslexia Research Foundation. A warm thanks to Mia Harbo for help in typing the manuscript, and I have greatly appreciated the contact with Liv Engen, Ingjerd Høien Tengesdal, Gunnar Tønnesen, and Ingebjørg Tønnesen, who throughout these years have encouraged me and supported me whenever I needed it. I am also highly indebted to Michael Evans for qualified help when preparing the English text of the thesis.

I also want to thank all children, parents and teachers who have been involved in the present study. Finally, a deep thanks to family and friends for patience and encouragement during my time working with the thesis. 


\section{EMPIRICAL REPORTS:}

The present dissertation is based on the following empirical studies:

\section{$\underline{\text { Report I: }}$}

Sprugevica, I., \& Høien, T (in print). Enabling skills in early reading acquisition: A study of children in Latvian kindergartens. Reading and Writing: An Interdisciplinary Journal.

\section{$\underline{\text { Report II: }}$}

Sprugevica, I., \& Høien, T. (in print). Early phonological skills and how they predict reading acquisition: A follow-up study from kindergarten to the middle of grade 2. Scandinavian Journal of Psychology.

\section{Report III:}

Sprugevica, I., \& Høien, T. (submitted). Relations between enabling skills and reading comprehension: A follow-up study of Latvian students from first to second grade. Scandinavian Journal of Psychology. 


\section{ABSTRACT:}

In this thesis, three studies were performed in order to investigate the relationships between various enabling skills (phonemic awareness, rapid naming, short-term memory, and letter knowledge), and word decoding and reading comprehension in the Latvian language. The relationships between enabling skills and reading ability were examined in a concurrent evaluation as well as in a longitudinal design.

The first study showed that phonemic awareness, rapid naming, and short-term memory constitute separate factors. Among kindergarten children phonemic awareness and letter knowledge were the only factors that significantly explained concurrent variance in word and sentence reading, and impact from letter knowledge was more powerful than phonemic awareness. Neither rapid naming nor short-term memory had any significant impact on concurrent reading ability (Report I).

In the second, longitudinal study, phonemic awareness, rapid naming and short-term memory were used as the independent factors, with reading ability as the dependent variable. Both hierarchical regression analysis and growth curve analysis were employed in the statistical analyses, and again the result showed that only phonemic awareness had power to predict reading development from kindergarten to grade 2 in word reading as well as in sentence reading (Report II).

In the third study reading comprehension assessed in the middle of grade 2 was used as the dependent variable, with phonemic awareness, rapid naming, and verbal-short memory, assessed in grade 1 as the independent variables. Structural modelling analysis showed that phonemic awareness had the strongest indirect impact on subsequent reading comprehension via word decoding, but no significant direct impact. However, it should be noted that rapid naming had both a direct and an indirect impact on reading comprehension. Short-term memory, again, did not have any significant impact on reading comprehension (Report III). 


\section{INTRODUCTION:}

\section{Reading acquisition:}

In modern society people pay a remarkable amount of attention to children's education. Most school programs are based on information from printed materials and children's ability to comprehend and use this kind of information. It is critical for children to learn to read because "mastery of such a remarkable system as written language has become a highly valued skill and prerequisite for success in our society" (Lundberg \& Høien, 1997).

Before addressing more explicitly questions regarding relationships between phonological skills, orthographic consistency, and early reading acquisition, we will briefly clarify the basic theory underlying the empirical studies.

Reading is a complex developmental challenge, which is intertwined with many other developmental accomplishments such as attention, memory, language, and motivation (Snow, Burns \& Griffin, 1998). Decoding and comprehension are different types of reading skill, but in normal, skilled reading they work closely together. Decoding allows the reader to recognise and pronounce the word, and thereby access its meaning. Comprehension applies not only to accurate understanding of the text (that is, the basic meaning of the text), but also to the reader's background knowledge about the situation described in the text (propositional meaning). Reading ability is the product of the both - decoding and comprehension. Gough and Tunmer (1986) have expressed this in their "Simple view of reading": Reading = decoding $x$ comprehension. If one of the factors is zero then the product is zero. Good reading ability needs both (Adams, 1990; Perfetti, 1985).

In the literature we find several theories of how reading ability develops through time (Chall, 1983; Ehri, 1992; Frith, 1985; Gough \& Hillinger, 1980; Spear-Swerling \& Sternberg, 1996). Høien and Lundberg $(1988,2000)$ provide a basic understanding of the conditions for the emergence of word decoding strategies. Therefore, their model will be described in more detail. They suggest the following four stages in reading development - the pseudo-reading stage, the logographic-visual stage, the alphabetic-phonemic stage and the orthographicmorphemic stage. 
At the pseudo-reading stage young preschool children are not aware of letters at all, but they nonetheless can recognise some familiar words, e.g. mom, his/her name, based on their contextual clues.

At the logographic stage children have still not grasped the alphabetic principle, and they treat each word as an independent visual stimulus. For them, learning to identify words is a kind of stimulus-response learning. This learning is based on fairly simple associations between a graphical pattern (logographs) and the name of the word. In order to move on to the next level, the alphabetic-phonemic stage, children need to learn to manipulate units of the words. When children have acquired this skill, they are able to isolate and attend to individual phonological segments and to manipulate letters. In order to identify the grapheme-phoneme correspondence rules, that is, how a letter-sequence represents a sound-sequence - it is first necessary to be able to pick out the units of sound (phonemes) in a word as it is pronounced and the units of spelling (graphemes) in the word as it is written. Gradually children start to discover some kind of patterns (familiar chunks) in words read frequently (Adams, 1990; Goswami \& Bryant, 1990). That gives them ability to use orthographic structure of word (for example, morphemes) to recognise a lot of words instantly without having to sound them out phoneme-by-phoneme. This allows the decoding process to become automated. This automaticity is the hallmark of skilful reading (Adams, 1990; LaBerge \& Samuels, 1974; Wolf, 2001). Proficient word decoding depends primarily on efficient phonological and orthographic decoding ability (Share, 1995; Share \& Stanovich, 1995; Tunmer \& Chapman, 1995), although if the word appears in a context, contextual cues may be used when decoding unfamiliar words.

During recent years a considerable amount of knowledge has been accumulated about the reading process and which subskills are critical for acquiring efficient reading ability (Kamil, Mosenthal, Pearson \& Barr, 2000). However, most of the research data regarding relationships between enabling skills and reading acquisition have been collected among children with English as first language (for overview, see Blachman, 1997). English is a language with rather low transparency, i.e. it is characterized by low consistency in grapheme-phoneme correspondences. Because of these biases in the data, more studies are needed regarding the relationship between enabling skills and languages with more consistent orthographies (Wimmer, 1993; Wimmer \& Goswami, 1994). 
The theory underlying the studies presented here (Høien \& Lundberg, 2000), considers reading as an unnaturally occurring part of any child's development. Learning to read does not develop spontaneously, but requires human intervention and context. While skilful readers seem to read 'naturally', the act of reading is in reality highly complex and intentional; it requires the bringing together of a number of complex actions involving the eyes, the brain, and the mind (e.g., motivation, interest, prior experience) that do not occur naturally (for overview, see Blachman, 1997; McGuinness, 1997; Snow et al., 1998). Therefore, the hypothesis that acquiring reading ability is a natural process pretty much similar to the process of learning to speak (Goodman, 1976) has gained little support in current reading research.

\section{Enabling skills and early reading acquisition:}

Although many factors influence the course of reading acquisition, a growing body of research has shown that some enabling skills are strong predictors of early reading success (for a review, see Adams, 1990; Lundberg, Frost \& Petersen, 1988; McGuinness, 1997; Wagner, 1988). Predictors are understood as "skills or abilities that have been demonstrated to contribute to reading development, and which are in themselves definable, measurable, and potentially modifiable through teaching“ (Muter, 2000). Especially four enabling skills have been at the focus of interest: Phonological awareness, rapid naming, short-term memory, and letter knowledge.

\section{Phonological awareness:}

It is well documented that measures of phonological awareness measures are strongly related to early reading acquisition (for overview, see Brady, 1997; Wagner, Torgesen, Rashotte, Hecht, Barker, Burgess, Donahue \& Garon, 1997).

The term phonological awareness refers to the ability to extract and manipulate small segments of spoken language. Many studies have shown that measures of phonological awareness in preliterate children can successfully predict later reading achievement (Badian, 
2000; Blachman, 1984; Lundberg et al., 1988; Snow et al., 1998; Stanovich, Cunningham \& Cramer, 1984). Even when variance in prior word reading skill is partialed out, early phonological awareness still predicts significant variance in subsequent word and nonword reading as well as in reading comprehension (Torgesen, Wagner \& Rashotte, 1997).

In order to understand how phonological awareness would predict early reading acquisition is necessary to explore different forms of this skill and how they would be accessed. Bentin (1992) suggests that the tests assessing phonological awareness may differ along at least three dimensions: operation required (for example, isolation of phonological segment of the word or detection), manner of testing of phonological awareness (indirect or explicit aptitude), size of the operated segment (for example, whether the operated segment is a syllable or a phoneme). Indirect aptitude means the sensitivity to sub-word phonological segments, although awareness of those segments is not directly tested (for example, rhyme detection). Explicit aptitude refers to the direct detection of the words' phonemes (for example, phoneme segmentation or deletion). On the basis of how phonological skills are measured Adams (1990) indicates four types of these skills: syllable and phoneme segmentation tasks (for example, the child is asked to count syllables in the word), phoneme manipulation tasks (for example, the child has to delete a specific phoneme from the word), sound blending tasks (the child is asked to synthesize the phonemes), and rhyming tasks (for example, the child has to identify the "odd word out").

The phonological difficulties may have different consequences for words decoding depending on the degree of grapheme-phoneme consistency characterising the language (Müller \& Brady, 2001). Orthographies can be put on an orthographic depth continuum from transparent to deep structure. Transparent, or consistent, languages have almost perfect phonemegrapheme correspondences, where one grapheme almost always maps onto one phoneme and vice versa. When decoding words in a consistent language, Wimmer and Landerl (1997) hypothesise that the decoding process more easily allows for phonological recording of words. The Latvian language is highly consistent in spelling. Each letter in general corresponds only to one phoneme. All vowel letters except two always encode the same vowel sounds. There are, however a few diphthongs in the language; therefore, the number of letters in a word is not always the same as the number of phonemes. Irregular words, however, occur very rarely in Latvian. Because the Latvian language is orthographically highly consistent, we assume that learning to decode words phonologically does not represent 
the same difficulties as those encountered by students having to learn a highly inconsistent language.

Why is phonological awareness such a powerful predictor of reading ability? One important aspect of phonological awareness entails the ability to shift perspective when dealing with words. When students are acquiring general language ability, it is important that they attend to the meaning of the words. But in order to learn to read, they have to attend to the phonology and orthography. This shift in perspective is a necessary for them to grasp the alphabetic principle, which is fundamental for when acquiring competence in phonological decoding. Especially phonemic awareness, which will be addressed in the next paragraph, plays a critical role in breaking the alphabetic code.

Phonemic awareness refers to the ability to segment a word into its constituent phonemes and to consciously manipulate these linguistic units. Phonemic awareness is a type of phonological awareness, but because it entails a special, measurable skill, we will include it as a separate term. Most studies have concluded that phonemic awareness is the single most important phonological factor underlying efficient reading acquisition (Brady, 1997; Lundberg \& Høien, 2001; Share \& Stanovich, 1995; Wagner et al., 1997), and skill in phonemic awareness in preliterate children can successfully predict later reading achievement (for overview, see Badian, 2000; Lundberg et al., 1988; Snow et al., 1998). Finally, difficulties in phonemic awareness have also been identified as the most critical factor underlying the severe word-decoding problems displayed by reading-disabled individuals (for overview, see Adams, 1990; Blachman, 2000; Rack, Snowling \& Olson, 1992; Snowling, 1981, 2000).

\section{Rapid naming:}

Rapid naming is another phonological skill, which has been studied as a predictor and a correlate of reading performance, and it has also been considered as a measure sensitive to subtypes of reading disability children (Wolf, 1997). Rapid naming refers to the ability to retrieve words very quickly. It is usually assessed through the ability to name colours, letters, numbers and objects quickly upon their presentation. Rapid naming skill is considered relevant to reading because it is indicative of how readily children can visually decode and 
gain access to the phonological and semantic identities representing the target item (Bowers \& Swanson, 1991; Cornwall, 1992). Thus, rapid naming may have an impact on both word decoding and reading comprehension.

The question of whether or not skill in rapid naming is distinct from other phonological skills has been the focus of considerable attention in recent research (Cutting \& Denckla, 2001; Muter \& Snowling, 1998; Wolf, 2001). Wagner and Torgesen (1987) assumed them both to be a reflection of a unitary phonological process. Other researchers, however, did not find any strong correlation between these two skills (Badian, 1993; Cornwall, 1992; Felton \& Brown, 1990). This suggests that rapid-naming tasks appear to measure something separate from phoneme awareness (for overview, see Wolf, 2001). Students who have problems with both tasks tend to be at the lowest end of the reading continuum, indicating that a "double-deficit" may cause these severe reading difficulties (Wolf \& Bowers, 1999). In this thesis this issue will be addressed.

Scarborough's (1998) review of longitudinal studies indicates that rapid naming was at least as strongly related to later reading skills as letter name knowledge and phonological awareness. It might be the case that the relationship between rapid naming is age-dependent. Pennington, Cardoso-Martins, Green and Lefly (2001) hypothesised that variation in rapid serial naming was particularly important at the stage when the student employs an orthographic strategy when decoding words, whereas phonemic awareness was more important when decoding words phonologically.

It is not difficult to understand that rapid naming and word reading may be related to each other, since both skills share some common cognitive-linguistic processes. In addition to attention control and visual processing, both skills require ability to activate and retrieve phonological and articulatory identities (Bowers \& Wolf, 1993). But inefficient word decoding will also impede reading comprehension. A slow and faulty word decoding process consumes cognitive resources, leaving less mental resources available for the comprehension process (for overview, see Høien \& Lundberg, 2000; Stothard \& Hulme, 1992).

Most studies addressing the impact of rapid naming skill on reading achievement have been carried out on English-speaking children in school age. This is unfortunate in that English has an orthographic system that is less regular than many other languages. It could be the case that 
students learning to read in an orthographically regular language like Latvian, that is a language with a written system that mirrors the phonology more consistently than in English, may learn to read in slightly different ways and at slightly different rates. A subskill like rapid naming may impact differently on Latvian children than on children in the US or UK.

Many studies on the impact of rapid naming have been done among dyslexic students (Snyder \& Downey, 1995), but fewer studies have also addressed the relationship between rapid naming and word reading among normally developing readers (Cutting \& Denckla, 2001). However, the naming speed differences between skilled and less-skilled readers are not yet resolved (Meyer, Wood, Hart \& Felton, 1998; Scarborough, 1998; Wolf, 1997).

\section{Short-term memory:}

A third enabling skill that has been considered important for reading acquisition is short-term memory. It is well known that children with dyslexia are scoring low on simple short-term memory tests, for example the digit-span subtest on WISC-R (Wagner \& Torgesen, 1987). The question is whether or not difficulties in short-term memory can explain variance in word performance also among children not defined as having dyslexia.

Before addressing more explicitly questions regarding relationships between short-term memory and reading acquisition, we would like to point out some aspects of the different terms used for describing memory (for overview, see Neath, Brown, Poirier \& Fortin, 1999). The term phonological memory refers to the retention of verbal information in a phonological code in a temporary memory system. Earlier studies described this as a verbal short-term memory and usually used span measures, e.g. repeating back a short list of digits or words, as the means of measurement. Also in this study span tests were used as a short-term memory indicator. Subsequently conceptualisation have extended the construct going beyond the passive storage of verbal input to a more active work space (called working memory), which serves perception, sentence analysis, information retrieval from a long-term memory, assembly of spoken output and elements of spoken or written language use. Reduced capacity or impaired quality of phonological information in the phonological memory has been hypothesised as corresponding to reading disability (Brady \& Shankweiler, 1991; Gathercole 
\& Baddeley, 1993; Hansen \& Bowey, 1994; Hanten \& Martin, 2001; Pennington, van Orden, Kirson \& Haith, 1991).

The child's ability to memorise and repeat verbal information has also been used as a predictor of reading achievement. It is well known that reading ability and short-term memory are significantly correlated (Wagner \& Torgesen, 1987), and Scarborough (1998) also refers to several studies showing that verbal short-term memory significantly predicts later reading ability. However, there are some studies which show that short-term memory is not significantly related to reading when phonemic awareness is partialed out (Wagner, Torgesen $\&$ Rashotte, 1994). Methodological issues can probably explain some of the dissonance in the results reported.

Short-term memory, and primarily working memory, is also important when constructing meaning above the level of identifying single words (McDougal \& Hulme, 1994; Oakhill \& Yuill, 1996; Scanlon \& Vellutino, 1997; Stothard, 1994). For example, when reading sentences, the reader needs to have lexical access to the phonological and semantic identities of many words at the same time (Willis \& Gathercole, 2001). The short-term memory also stores phonological identities at the word level, and this information is critical for obtaining success when reading and interpreting sentences. For example, a student reading a sentence in a text must have access to previously mentioned actors and objects in order to grasp who or what the pronouns are referring to. $\mathrm{He} /$ she also needs contextual information to integrate coherently the information presented in the current sentence with the information previously read. Therefore, a reader may be unable to comprehend a written sentence even when he/she has lexical access to each single word in the sentence (Stothard \& Hulme, 1992; Yuill \& Oakhill, 1991).

In the present thesis digit-span and letter-span tasks were employed, as indeed they often are in reading research, but it has to be taken into account that span-tasks only assess a restricted area of working memory.

All three enabling skills mentioned above may have both an indirect and a direct impact on reading comprehension. The indirect impact goes through variance in word decoding, and it is clearly documented that word decoding and reading comprehension are highly correlated (for overview, see Adams, 1990; Snowling, 2000). Due to the fact that abilities in phonological 
skills, and primarily ability in phonemic awareness, play a critical role in acquiring word decoding competence (see Stanovich, 2000), we may assume that phonological skills have a substantial indirect impact on reading comprehension. For example, in a recent study, Engen and Høien (in print) found that phonemic awareness also had a direct impact on reading comprehension in addition to the indirect impact via word decoding ability. The direct and indirect impact of the phonological skills on reading comprehension among young children using a highly consistent language, is an issue of concern in the present thesis.

\section{Letter knowledge:}

Research has also provided convincing evidence that letter knowledge accounts for a substantial part of the variance in word recognition (Gallagher, Frith \& Snowling, 2000; Muter, Hulme, Snowling \& Taylor, 1998). The term letter knowledge is defined as the ability to name the letter and / or to pronounce the sound of the letter.

There are at least two possible reasons why knowledge of letter names or sounds is an important predictor for children learning to read. Obviously, "knowledge of letter sounds is necessary for children to understand that there is a systematic relationship between the spelling patterns of words and their pronunciations" (Muter, 2000). Also, it can be assumed that young children are creating maps between the orthographic representations of words and their phonological forms, but for this process letter knowledge is necessary to "translate" words in their sounds' equivalents (Ehri, 1992; Rack, Hulme, Snowling \& Wightman, 1994).

Many recent studies have suggested that letter knowledge accounted for more variance in word decoding tasks than measures of phonemic awareness (Byrne \& Fielding-Barnsley, 1989; Muter, Hulme, Snowling \& Taylor, 1998). However, a large number of other researchers have reported that phonological skills are the major predictor of reading achievement (Wagner, 1988). Additionally, we have to point out that not only phonological skills and letter knowledge make separate and specific contributions to early literacy, but there is an additional significant contribution from the interaction of these skills (Muter et al., 1998). The interactive effect of letter knowledge and phonological skills (measured with segmentation tasks) was proposed by Hatcher, Hulme, and Ellis (1994) as "the phonological linkage hypothesis." Training children simultaneously on phonological awareness and letter 
names gives the best effect for reading progress, and we assume that this is true independently of the orthographic consistency of the target language.

\section{HYPOTHESES AND RESEARCH QUESTIONS:}

The following main issues were addressed in the present thesis:

- What are the interrelationships between phonemic awareness, rapid naming, and verbal short-term memory among Latvian students in kindergarten?

- What impact do phonological skills, assessed in kindergarten, have on concurrent word decoding and sentence reading when using a language having a highly consistent orthography?

- What is the power of phonemic awareness, rapid naming, and short-term memory, assessed among students in kindergarten, to predict subsequent reading skills (word reading and sentence reading) in the middle of grade 1 , at the end of grade 1 , and in the middle of grade 2 ?

- What power do phonemic awareness, rapid naming, and short-term memory have to predict the slope of the curves characterising word and sentence reading development from kindergarten to the middle of grade 2 ?

- What are the direct and indirect relationships between phonemic awareness, rapid naming, and short-term memory assessed among students in the middle of grade 1, and reading comprehension assessed in the middle of grade 2 ?

\section{COMMON METHODS AND DESIGNS:}

In the present studies, the children were followed up from kindergarten to the middle of grade 2 , and assessments were performed regularly at six-month intervals. In kindergarten 76 students ( 40 girls and 36 boys) participated, but at the end of the study (in the middle of grade 2), only 55 (29 girls and 26 boys) of the original children still were available for assessment. The dropping out of children seems to be rather random, primarily caused by parents moving 
to other cities in Latvia. All students were assessed individually with qualified assistants under the control of the project leader.

In reading research, various methods have been used to assess phonemic awareness (Adams, 1990; Yopp, 1988). In the phoneme deletion test the child has to identify and delete the first and the last phoneme of the target word and pronounce the word/nonword remaining after the deletion. In the phoneme isolation test the child has to isolate and pronounce the first or the last sound of well-known words, whereas the phoneme segmentation test assessed the child's ability to identify phonemes in orally presented words. In the present thesis phoneme deletion, phoneme isolation, and phoneme segmentation tests were used to get a latent measurement of phonemic awareness.

Two methods have been used in reading research for measuring rapid naming: confrontation naming and rapid serial naming (Wolf \& Bowers, 1999). When using confrontation naming, common objects or colours are presented one at the time on the computer screen, and the response time, that is the time between presentation of the item and when the voice key is activated by the child's oral response, is recorded. When employing the rapid serial naming, all items are presented at the same time on the screen, and the child has to name as many of the items as possible during a restricted time interval (e.g. 2 minutes). Although both methods have some similarity (for example both tests measure the ability to visually identify the object, activate and retrieve the phonological identity corresponding to the item, and articulate the word), the rapid serial naming also involves additional processes, for example visual scanning the string of objects. In reading research, the rapid-serial naming methods have been most often used, and we therefore decided to use this method in our work. Objects and colours were used in the statistical analysis to get a latent variable representing rapid naming.

As already mentioned, when assessing short-term memory, the traditional digit-span test was used. This test is well known from WISC-R (Wechsler, 1974), and it is well documented that dyslexic children score low on this subtest. However, it has to be kept in mind that the main focus in the present studies was to address the possible relationship between short-term memory and reading ability in a broader sense.

In the present thesis both cross-sectional and longitudinal designs were used. The dependent variables were measures of reading skills (achievement in reading words, sentences, and 
texts), whereas phonemic awareness, rapid naming, and short-term memory represented the independent variables.

When investigating the impact of early predictors on later reading achievement, most studies have used traditional correlation analyses. Some studies, however, have addressed the relationship between early predictors and the growth curve characterising the reading development. Growth-curve analysis provides information about the parameters of the best fitting curve of individual reading development, such as the linear slope. By further statistical analyses, for example hierarchic regression analysis, the individual slope values can be used as a dependent variable to find which predictor factors are most powerful in explaining the growth of reading development (Jacobson \& Lundberg, 2000).

One way to conceptualise the relationship between a variable's direct and indirect impact with the other variables is in the terms of structural analysis (Steiger, 1989). When employing latent variable measurement with more than one manifest indicator errors of measurement are corrected for (cf. correction for attenuation). Thus, the relationships between latent variables are in a sense error free and not masked by unreliability.

\section{SUMMARY OF THE EMPIRICAL REPORTS:}

\section{Report I:}

76 preschool children ( 40 girls and 36 boys) in Latvia were tested in order to examine the relationships among various enabling skills and early reading achievement. The children were randomly selected from four different kindergartens in the city of Riga. They ranged in age from 6 to 7 years. Only children from mono-linguistic Latvian-speaking families were included in the study. The test battery included nine measures to assess phonological skills: rhyming, syllable counting, phoneme deletion, phoneme isolation, phoneme segmentation, object naming and color naming tests, digit-span and letter-span tests. Three tasks were used to assess reading skills: letter knowledge, word decoding and sentence reading. 
One of the aims of this study was to examine the relationship between the various types of phonological skills. A principal component analysis gave three latent factors: a phonemic awareness factor, a rapid naming factor, and a short-term memory factor.

The factor scores obtained were used in the hierarchical regression analyses. Only phonemic awareness accounted significantly for unique variance in the reading tasks. Neither naming nor short-term memory contributed to explain additional variance in reading performance.

However, when letter knowledge was entered into the equation as an independent variable, the results replicated previous findings showing that letter knowledge is the most powerful factor predicting reading ability.

In sum, the main finding in the first study was that phonemic awareness and letter knowledge assessed in kindergarten were the most powerful predictors of concurrent word reading ability in an orthographically consistent language like Latvian.

\section{Report II:}

The aim of this study was to investigate the power of early measures of phonological skills (phonemic awareness, rapid naming, short-term memory) in predicting later reading skills at various points of time. 70 kindergarten children ( 39 girls and 31 boys), with an age range from 6 to 7 years, were followed from kindergarten to the middle of $2^{\text {nd }}$ grade. The assessments were repeated twice a year.

The test battery included two measures of reading skills: word decoding and sentence reading, and six measures of phonological skills: phoneme deletion and segmentation tests, object naming and color naming tests, digit-span and letter-span tests. In further statistical analyses the raw scores of the tests were transformed into composite scores representing phonemic awareness, rapid naming and short-term memory.

Two different statistical methods were applied to study the predictive power of kindergarten assessment of phonological skills: regression analyses and growth curve analyses. 
In the hierarchical regression analysis, phonemic awareness in kindergarten explained about $27 \%$ of the variance in word reading six months later and about $9 \%$ of the variance at the end of $1^{\text {st }}$ grade. Even when prior level of reading skill was included in the equation, a significant amount of variance was still explained by phonemic awareness. When using sentence reading as the dependent variable, phonemic awareness explained about $16 \%$ of unique variance after six months, and about $13 \%$ of the variance in the middle of $2^{\text {nd }}$ grade.

Phonemic awareness was also the only phonological factor that accounted for significant variance in the word reading slope, explaining about $15 \%$ of the variance in word reading development. However, phonemic awareness did not predict the slope of the sentence curve. The other predictor variables did not explain additional variance, neither in the development of word reading nor in sentence reading.

\section{Report III:}

The enabling skills may have both an indirect and a direct impact on reading comprehension. The indirect impact goes via word decoding, whereas the direct impact goes directly from the enabling skills to reading comprehension.

The aim of the study was to examine the direct and indirect impact of enabling skills assessed in kindergarten on reading comprehension assessed one year later. The students ( 29 girls and 26 boys) were followed from the middle of grade 1 to the middle of grade 2 . They were assessed with a battery of enabling tasks and reading comprehension tests. A principal component analysis of the phonological tasks revealed three separate factors: phonemic awareness, rapid naming, and short-term memory factor. A structural modelling analysis (EZPath) was used when analyzing the direct and indirect relationship between latent variables. Indirectly both phonemic awareness and rapid naming explained unique variance in reading comprehension, but phonemic awareness was most powerful. However, phonemic awareness did not have any direct impact on reading comprehension. Thus, our results did not verify research findings that phonemic awareness also has a direct impact on reading comprehension. 
It is noteworthy that rapid naming had a direct impact on reading comprehension, accounting for about $6 \%$ of unique variance. Our study showed that rapid naming assessed in grade 1 had the power to predict some variance in reading comprehension one year later. When summarising the direct and indirect impact on reading comprehension, our findings show that phonemic awareness and rapid naming contributed to explain approximately the same amount of unique variance in the dependent variable. Therefore, a test battery in grade 1 should also include a test assessing rapid naming.

\section{OVERALL DISCUSSION AND CONCLUSIONS:}

It should be mentioned that the number of students participating in the studies was rather small. Multivariate regression analyses, growth curve analyses and structural modelling require larger groups to yield stable and reliable results. Cross validations are certainly called for. A more comprehensive study would also have allowed for more sophisticated analyses, for example, with focus on different subgroups of reading-disabled students.

With these limitations in mind, we will sum up the main findings:

1) Among children in Latvian kindergartens, a principal component analysis gave three separate phonological enabling skills: phonemic awareness, rapid naming, and shortterm memory (Report I).

2) The results of multiple regression analyses revealed that among phonological factors only phonemic awareness accounted significantly for unique variance in concurrent word and sentence reading. Neither naming nor short-term memory contributed to explain any variance in these reading tasks (Report I).

3) When letter knowledge was entered into the equation it accounted for more variance in word decoding tasks than measures of phonemic awareness (Report I). 
4) Phonemic awareness assessed in kindergarten has power to predict significantly word and sentence reading ability in grade 1 and grade 2 . Neither naming nor short-term memory had any predictive power (Report II).

4) When using growth curve analysis, phonemic awareness assessed in kindergarten was the only factor that significantly predicted the curve slopes for word decoding (Report II).

5) The structural modelling analysis showed that both phonemic awareness and rapid naming assessed in grade 1 had a significant indirect impact on reading comprehension one year later. However, only rapid naming contributed directly to explain any variance in reading comprehension (Report III).

The general aim of this thesis was to focus on some of the aspects of the relationships between various enabling skills and early reading acquisition in the Latvian language. The present thesis adds further evidence to the critical role played by phonemic awareness in reading acquisition, and our findings also showed that the importance of phonemic awareness does not depend on the orthographic consistency characterizing the language used in the study.

The mutual relations between different types of phonological skills also were investigated. The results in our thesis give some support to researchers who hypothesize that phonemic awareness and rapid naming are distinct phonological skills and that both skills provide a unique contribution in explaining efficient reading ability (for overview, see Wolf, 2001).

Furthermore, the power of early measures of phonological skills (phonemic awareness, rapid naming, short-term memory) was assessed in relation to concurrent and later reading skills. In our studies phonemic awareness assessed in kindergarten accounted for concurrent variance in word or sentence reading and predicted subsequent variance in them as well. Even when letter knowledge was entered into the equation, still phonemic awareness explained unique variance in word decoding among kindergarteners. 
Rapid naming did not account for subsequent variance in word or sentence reading, but it is noteworthy that rapid naming assessed in grade 1 was the only phonological factor having a direct impact on reading comprehension one year later.

No direct or indirect relationships were found between short-term memory and reading comprehension. This result was somewhat surprising. However, as mentioned, the simple short-term memory tasks used in the present study (digit-span and letter-span tasks) are probably not powerful enough to capture the more critical working memory processes involved when reading connected text (Oakhill \& Yuill, 1996; Stothard \& Hulme, 1992).

Nevertheless, among all predictors of early reading skills letter knowledge accounted for more variance in word decoding tasks than measures of phonological skills. Thus, the present results are in agreement with the findings, showing the power of letter knowledge to explain variance in early reading acquisition and that phonemic awareness and letter knowledge makes separate and specific contributions to beginning literacy (see also Frost, 2001).

In the present thesis the focus has been on the relationship between enabling skills and reading acquisition. However, the psychological research has to be supplemented with biological studies to acquire information about the neurological mechanisms underlying deficits in enabling skills and difficulties learning to read. Recent research in this field has made important progress (Galaburda, 1989; Hugdahl \& Heiervang, 1999; Nicolson \& Fawcett, 1999), but it is still important for further research to increase our knowledge about the impact of biological processes on the acquisition of enabling skills and skilful reading.

Finally, the present thesis had a goal to widen the understanding of how would be predicted early reading skills in consistent orthography. The results give some support to researchers who hypothesize that distinct phonological skills can predict successfully reading ability at the one time points but fail - at another. Whereas phonemic awareness is a good predictor already among kindergarten children, rapid naming might be a more powerful predictor of subsequent orthographic reading. Therefore, a diagnostic reading test should include phonemic awareness and rapid naming tasks, as well as tasks assessing letter knowledge. Such a diagnostic test may be very useful when planning appropriate remedial intervention. 


\section{REFERENCES:}

Adams, M. (1990). Beginning to read: Thinking and learning about print. Cambridge, MA: MIT Press.

Badian, N. (1993). Phonemic awareness, naming, visual symbol processing, and reading. Reading and Writing: An Interdisciplinary Journal, 5, 87-100.

Badian, N. (Ed.) (2000). Prediction and prevention of reading failure. Baltimore, Maryland: York Press.

Bentin, S. (1992). Phonological awareness, reading and reading acquisition: A survey and appraisal of current knowledge. In R. Frost \& L. Katz (Eds.), Orthography, phonology, morphology, and meaning (pp. 193-210). Amsterdam: North-Holland.

Blachman, B. (1984). Relationship of rapid naming ability and language analysis skills to kindergarten and first-grade reading achievement. Journal of Educational Psychology, $76,610-622$.

Blachman, B. (Ed.) (1997). Foundations of reading acquisition and dyslexia, implications for early intervention. Mahwah, $\mathrm{NJ}$ : Erlbaum.

Blachman, B. (2000). Phonological awareness. In M. Kamil, P. Mosenthal, P. Pearson \& R. Barr (Eds.), Handbook of Reading Research. Volume III (pp. 483-502). Mahwah, NJ: Erlbaum.

Bowers, P. \& Swanson, L. (1991). Naming speed deficits in reading disability: Multiple measures of a singular process. Journal of Experimental Child Psychology, 51, 195219.

Bowers, P. \& Wolf, M. (1993). Theoretical links among naming speed, precise timing mechanisms and orthographic skill in dyslexia. Reading and Writing: An Interdisciplinary Journal, 5, 69-85.

Brady, S. (1997). Ability to encode phonological representations: An underlying difficulty of poor readers. In B. Blachman (Ed.), Foundations of reading acquisition and dyslexia. Implications for early intervention (pp. 21-47). Mahwah, NJ: Erlbaum.

Brady, S. \& Shankweiler, D. (Eds.) (1991). Phonological processes in literacy. Hillsdale, NJ: Erlbaum.

Byrne, B. \& Fielding-Barnsley, R. (1989). Phonemic awareness and letter knowledge in the child's acquisitions of the alphabetic principle. Journal of Educational Psychology, $81,313-321$. 
Chall, J. (1983). Stages of reading development. New York: McGraw-Hill.

Cornwall, A. (1992). The relationship of phonological awareness, rapid naming, and verbal memory to severe reading and spelling disability. Journal of Learning Disabilities, 25 , 532-538.

Cutting, L. \& Denckla, M. (2001). The relationship of rapid serial naming and word reading in normally developing readers: An exploratory model. Reading and Writing: An Interdisciplinary Journal, 14, 673-705.

Ehri, L. (1992). Reconceptualizing the development of sight word reading and its relationship to recoding. In. P. Gough, L. Ehri \& R. Treiman (Eds.), Reading acquisition (pp. 107143). Hillsdale, NJ: Erlbaum.

Engen, L. \& Høien, T. (in print). Phonological skills and reading comprehension. Reading and Writing: An Interdisciplinary Journal.

Felton, R. \& Brown, I. (1990). Phonological processes as predictors of specific reading skills in children at risk for reading failure. Reading and Writing: An Interdisciplinary Journal, 2, 39-59.

Frith, U. (1985). Beneath the surface of developmental dyslexia. In K. Patterson, J. Marshall, \& M. Coltheart (Eds.), Surface dyslexia: Neuropsychological and cognitive studies of phonological reading (pp. 301-330). London: Erlbaum.

Galaburda, A. (1989). From Reading to Neurons. Cambridge, MA: MIT Press.

Gallagher, A., Frith, U. \& Snowling, M. (2000). Precursors of literacy delay among children at risk of dyslexia. Journal of Child Psychology and Psychiatry, 41, 203-213.

Gathercole, S. \& Baddeley, A. (1993). Working memory and language. Hove, England: Erlbaum.

Goodman, K. (1976). A psycholinguistic guessing game. In H. Singer \& R. Ruddell (Eds.), Theoretical models and processes of reading (pp. 497-508). Newark: DE: International Reading Association.

Goswami, U. \& Bryant, P. (1990). Phonological skills and learning to read. Hove, England: Erlbaum.

Gough, P. \& Hillinger, M. (1980). Learning to read: An unnatural act. Bulletin of the Orton Society, 30, 171-176.

Gough, P. \& Tunmer, W. (1986). Decoding, reading, and reading disability. Remedial and Special Education, 7, 6-10.

Hansen, J. \& Bowey, J. (1994). Phonological analysis skills, verbal working memory, and reading ability in second-grade children. Child Development, 65, 938-950. 
Hanten, G. \& Martin R. (2001). A developmental phonological short-term memory deficit: A case study. Brain and Cognition, 45, 164-188.

Hatcher, P., Hulme, C. \& Ellis, A. (1994). Ameliorating early reading failure by integrating the teaching of reading and phonological skills: The phonological linkage hypothesis. Child Development, 65, 41-57.

Hugdahl, K. \& Heiervang, E. (1999). Brain markers of dyslexia: Planum temporale asymmetry and dichotic listening to CV-syllables. In I. Lundberg, F. Tønnessen \& I. Austad (Eds.), Dyslexia: Advances in theory and practice (pp. 157-172). Dordrecht: Kluwer Academic Publishers.

Høien, T. \& Lundberg, I. (1988). Stages of word recognition in early reading acquisition. Scandinavian Journal of Educational Research, 32, 163-182.

Høien, T. \& Lundberg, I. (2000). Dyslexia: From theory to intervention. Dordrecht: Kluwer Academic Publishers.

Jacobson, C. \& Lundberg, I. (2000). Early prediction of individual growth in reading. Reading and Writing: An Interdisciplinary Journal, 13, 273-298.

Kamil, M., Mosenthal, P., Pearson, P. \& Barr, R. (2000). Handbook of Reading Research. Volume III. Mahwah, NJ: Erlbaum.

LaBerge, D. \& Samuels, S. (1974). Toward a theory of automatic information processing in reading. Cognitive Psychology, 6, 293-323.

Lundberg, I., Frost, J. \& Petersen, O.P. (1988). Long term effects of a preschool training program in phonological awareness. Reading Research Quarterly, 28, 263-284.

Lundberg, I. \& Høien, T. (1997). Levels of approaching reading and its difficulties. In B. Ericson \& J. Rönnberg (Eds.), Reading disability and its treatment (pp. 11-36). Linköping: Läspedagogiska Institutet EMIR.

Lundberg, I. \& Høien, T. (2001). Dyslexia and phonology. In A. Fawcett (Ed.), Dyslexia: Theory and good practice (pp. 109-123). London: Whurr.

McDougal, S. \& Hulme, C. (1994). Short-term memory speech rate and phonological awareness as predictors of learning to read. In C. Hulme \& M. Snowling (Eds.), Reading development and dyslexia (pp. 31-44). London: Whurr.

McGuinness, D. (1997). Why our children can't read: And what we can do about it. New York: The Free Press.

Meyer, M., Wood, F., Hart, L. \& Felton, R. (1998). Selective predictive value of rapid automatized naming in poor readers. Journal of Learning Disabilities, 31, 106-117. 
Muter, V. (2000). Screening for early reading failure. In N. Badian (Ed.), Prediction and prevention of reading failure (pp. 1-29). Baltimore, Maryland: York Press.

Muter, V., Hulme, C., Snowling, M. \& Taylor, S. (1998). Segmentation, not rhyming predicts early progress in learning to read. Journal of Experimental Child Psychology, 71, 327.

Muter, V. \& Snowling, M. (1998). Concurrent and longitudinal predictors of reading: The role of metalinguistic and short-term memory skills. Reading Research Quarterly, 33 , 320-337.

Müller, K. \& Brady, S. (2001). Correlates of early reading performance in a transparent orthography. Reading and Writing: An Interdisciplinary Journal, 14, 757-799.

Neath, I., Brown, G., Poirier, M. \& Fortin, C. (1999). Short-term/working memory: An overview. International Journal of Psychology, 34, 273-275.

Nicolson, R. \& Fawcett, A. (1999). Developmental dyslexia: The role of the cerebellum. In I. Lundberg, F. Tønnessen \& I. Austad (Eds.), Dyslexia: Advances in theory and practice (pp. 173-196). Dordrecht: Kluwer Academic Publishers.

Oakhill, J. \& Yuill, N. (1996). Higher order factors in comprehension disability: In C. Cornoldi \& J. Oakhill (Eds.), Reading comprehension difficulties. Processes and intervention (pp. 69-92). Mahwah, NJ: Erlbaum.

Pennington, B., Cardoso-Martins, C., Green, P. \& Lefly, D. (2001). Comparing the phonological and double deficit hypotheses for developmental dyslexia. Reading and Writing: An Interdisciplinary Journal, 14, 707-755.

Pennington, B., Van Orden, G. Kirson, D. \& Haith, M. (1991). What is the causal relation between verbal STM problems and dyslexia? In S. Brady \& D. Shankweiler (Eds.), Phonological processes in literacy (pp. 173-186). Hillsdale, NJ: Erlbaum.

Perfetti, C. (1985), Reading ability. New York: Oxford University Press.

Rack, J., Hulme, C., Snowling, M. \& Wightman, J. (1994). The role of phonology in young children learning to read words: The direct mapping hypothesis. Journal of Experimental Child Psychology, 57, 42-71.

Rack, J., Snowling, M. \& Olson, R. (1992). The nonword reading deficit in developmental dyslexia: A review. Reading Research Quarterly, 27, 28-53.

Scanlon, D. \& Vellutino, F. (1997). Instructional influences on early reading success. Perspectives. The International Dyslexia Association, 23, 35-37.

Scarborough, H. (1998). Early identification of children at risk for reading disabilities: Phonological awareness and some other promising predictors. In B. Shapiro, P. 
Accardo, \& A. Capute (Eds.), Specific Reading Disability: A View of the Spectrum (pp. 77-121). Timonium: MD: York Press.

Share, D. (1995). Phonological recoding and self-teaching: Sine qua non of reading acquisition. Cognition, 55, 151-218.

Share, D. \& Stanovich, K. (1995). Cognitive processes in early reading development. Issues of Education: Contributions from Educational Psychology, 1, 1-57.

Snow, C., Burns, M. \& Griffin, P. (Eds.) (1998). Preventing reading difficulties in young children. Washington DC: National Academy Press.

Snowling, M. (1981). Phonemic deficits in developmental dyslexia. Psychological Research, $43,219-234$.

Snowling, M. (2000). Dyslexia. Oxford: Blackwell.

Snyder, L. \& Downey, D. (1995). Serial rapid naming skills in children with reading disabilities. Annals of Dyslexia, 45, 31-50.

Spear-Swerling, L. \& Sternberg, R. (1996). Off track. When poor readers become "learning" disabled". Boulder, CO: Westview Press.

Stanovich, K. (2000). Progress in understanding reading. Scientific foundations and new frontiers. New York: The Guilford Press.

Stanovich, K., Cunningham, A. \& Cramer, B. (1984). Assessing phonological awareness in kindergarten children: Issues of task comparability. Journal of Experimental Child Psychology, 38, 175-190.

Steiger, J. (1989). EzPath, Causal modeling. A supplementary module for SYSTAT and SYGRAPH. Evanston, Illinois: Systat, Incorporation.

Stothard, S. (1994). The nature and treatment of reading comprehension difficulties in children. In C. Hulme \& M. Snowling (Eds.), Reading development and dyslexia (pp. 200-238). London: Whurr.

Stothard, S. \& Hulme, C. (1992). Reading comprehension difficulties in children. Reading and Writing: An Interdisciplinary Journal, 4, 245-256.

Torgesen, J., Wagner, R. \& Rashotte, C. (1997). Contribution of phonological awareness and rapid automatic naming ability to the growth of word-reading skills in second- to fifthgrade children. Scientific Studies of Reading, 1, 161-185.

Tunmer, W. \& Chapman, J. (1995). Context use in early reading development: Premature exclusion of a source of individual differences? Issues in Education, 1, 97-100. 
Wagner, R. (1988). Causal relations between the development of phonological processing abilities and the acquistion of reading skills: A meta-analysis. Merrill-Palmer Quarterly, 34, 261-279.

Wagner, R. \& Torgesen, J. (1987). The nature of phonological processing and its causal role in the acquisition of reading skills. Psychological Bulletin, 101, 192-212.

Wagner, R., Torgesen, J. \& Rashotte, C. (1994). The development of reading-related phonological processing abilities: New evidence of bi-directional causality from a latent variable longitudinal study. Developmental Psychology, 30, 73-87.

Wagner, R., Torgesen, J., Rashotte, C., Hecht, S., Barker, T., Burgess, S., Donahue, J., \& Garon, T. (1997). Changing relations between phonological processing abilities and word-level reading as children develop from beginning to skilled readers: A 5-year longitudinal study. Developmental Psychology, 33, 468-479.

Wechsler, D. (1974). Wechsler intelligence scale for children - revised. San Antonio, TX: Harcourt Brace, Jovanavich.

Willis, C. \& Gathercole, S. (2001). Phonological short-term memory contributions to sentence processing in young children. Memory, 9, 349-363.

Wimmer, H. (1993). Characteristics of developmental dyslexia in a regular writing system. Applied Psycholinguistics, 14, 1-33.

Wimmer, H. \& Goswami, U. (1994). The influence of orthographic consistency on reading development: Word recognition in English and German children. Cognition, 51, 91103.

Wimmer, J. \& Landerl, K. (1997). How learning to spell German differs from learning to spell English. In C. Perfetti \& L. Rieben (Eds.), Learning to spell: Research, theory, and practice across languages (pp. 81-96). Mahwah, NJ: Erlbaum.

Wolf, M. (1997). A provisional, integrative account of phonological and naming-speed deficits in dyslexia: Implications for diagnosis and intervention. In B. Blachman (Ed.), Foundations of reading acquisition and dyslexia: Implications for early intervention (pp. 67-94). Mahwah, NJ:Erlbaum.

Wolf, M. (Ed.) (2001). Dyslexia, fluency, and the brain. Timonium, Maryland: York Press.

Wolf, M. \& Bowers, P. (1999). The double-deficit hypothesis for the developmental dyslexia. Journal of Educational Psychology, 91, 415-438.

Yopp, H. (1988). The validity and reliability of phonemic awareness tests. Reading Research Quarterly, 23, 159-177. 
Yuill, N. \& Oakhill, J. (1991). Children's problems in text comprehension. Cambridge: Cambridge University Press. 


\title{
EMPIRICAL REPORTS
}

\section{Report I}

\section{Enabling Skills in Early Reading Acquisition: A Study of Children in Latvian Kindergartens}

\author{
IEVA SPRUGEVICA \\ University of Latvia, Riga, Latvia
}

TORLEIV HØIEN

Dyslexia Research Foundation, Stavanger, Norway

\begin{abstract}
Preschool children in Latvia were tested in order to examine the relationships among various enabling skills and early reading performance. A principal component analysis indicated three factors: a phonemic awareness factor, a naming factor, and a short-term memory factor. Multiple regression analyses with word identification and sentence comprehension as dependent variables yielded further support to the powerful role played by phonemic awareness in explaining variance in both these aspects of reading. Unexpectedly, neither naming nor short-term memory contributed to explain unique variance in word and sentence reading. The Latvian orthography is very consistent, and our results provide further evidence to the importance of phonemic awareness in early reading acquisition especially in a transparent language. Therefore, the tasks used when assessing phonemic awareness can be very useful when screening children at risk for developing reading problems. Enhancing children's letter knowledge and phonemic awareness skills should be a priority goal in the kindergarten classroom.
\end{abstract}

KEY WORDS: Phonological skills, Phonemic awareness, Verbal short-term memory, Naming, Letter knowledge, Reading, Word decoding, Sentence reading. 


\section{Introduction}

A growing body of research has shown that phonological awareness measures are strongly related to early reading acquisition (Brady 1997; Wagner, Torgesen, Rashotte, Hecht, Barker, Burgess, Donahue \& Garon 1997). The term phonological awareness refers to the ability to extract and manipulate small segments of spoken language. Many studies have shown that measures of phonological awareness, and especially phonemic awareness, in preliterate children can successfully predict later reading achievement (for overview, see Badian 2000). Phonemic awareness is a type of phonological awareness. It refers to the ability to identify and/or manipulate the separate phonemes constituting a word. Importantly, deficits in phonemic awareness have also been identified as the critical factor underlying the severe word-decoding problems displayed by reading-disabled individuals (for overview, see Stanovich 2000).

Various tasks have been used to measure phonological awareness. A question of concern is the relationship between the various types of skills that constitute phonological awareness. It may be the case that the various tasks used to assess these skills are differentially sensitive or differentially age-appropriate indicators of a unitary construct of phonological sensitivity (see e.g. Stanovich 1992). Alternatively, it could be the case that various phonological tasks in fact reflect different basic constructs (e.g. Bentin 1992). This is an issue to be addressed in the present study.

It is also obvious that other enabling skills that are not a part of phonological awareness influence the course of reading acquisition in pre-school age. Children with reading problems, for example, often have short-term memory problems (Baddeley 1986; Wagner \& Torgesen 1987), and have slower speed when naming familiar visual symbols (e.g. digits, letters, colors). (For overview, see Wolf 2001)

Most findings regarding the close connection between enabling skills and reading skills are based on studies among children and adults who have English as their native language (for a review, see Blachman 1997). English differs from many other alphabetic languages in its relatively low grapheme-phoneme consistency, but the orthographies vary concerning grapheme-phoneme consistency.

Orthographies can be put on an orthographic depth continuum from transparent to deep structure. Transparent, or consistent, languages have almost perfect phoneme-grapheme correspondences, where one grapheme always maps onto one phoneme. In deep orthographies 
where the same phoneme can be represented by different letters, English is considered to have a deep structure, whereas Finnish orthography represents a very transparent orthography.

The orthography of a language may have an impact on the relationship between enabling skills and early reading acquisition. For example, a transparent language is easier to decode than languages with a deep orthography, and it could be anticipated that phonological decoding will account less of the variance in learning to read. Landerl, Wimmer \& Frith (1997), for example, hypothesize that a higher degree of competency in phonological recoding skills is required when decoding words in an inconsistent language such as English, compared to a highly consistent language such as German. When decoding words in consistent languages, Wimmer and Landerl (1997) hypothesize that the decoding process more easily allows for the phonological recoding of words into syllables on-line. Some studies using languages with more consistent orthography than English (e.g. German, Italian, Serbo-Croatian, Turkish, and Greek) yield some support for this hypothesis (Cossu, Shankweiler, Liberman \& Gugliotta 1995; Wimmer 1993; Wimmer \& Goswami 1994).

However, this hypothesis may not accord with an early stage of reading acquisition. Obviously phonological skills are especially important when the child is learning to decode words. Therefore, differences in phonological skills at this stage may cause clear variance in word decoding achievement. The phonological strategy is normally acquired before the orthographic one (Frith 1985; Høien \& Lundberg 1988). Share (1995), for example, refers to the phonological strategy as a "self-teaching" mechanism that helps children to develop reading competence and gradually acquire a larger store of sight words. However, as soon as the fundamental phonological skills are acquired, variation in these probably will diminish, and consequently account for less of the variance in reading ability. In accordance with these assumptions, we hypothesize that phonological skills play an important role among children in kindergartens learning to read even when the language is highly transparent.

The Latvian language is highly consistent in spelling. Each letter in general corresponds only to one phoneme. All vowel letters except two always encode the same vowel sounds. For example, if a child knows the sound symbolized by the letter $u$, then he or she knows immediately the phoneme to use when reading off words such as upe, luga and eju. And conversely: when trying to spell these words, the child's own pronunciation will fairly unambiguously allow him/her to find the right letters. There are, however, a few diphthongs in the language; therefore, the number of letters in a word is not always the same as the number of phonemes. Irregular words, which are very frequent in English, occur very rarely 
in Latvian. In this respect Latvian is very different from English and very similar to highly transparent language.

The question of whether or not skill in rapid naming is distinct from other phonological skills has been the focus of considerable attention in recent research (Cutting \& Denckla 2001; Muter \& Snowling 1998; Wolf 2001). Wolf and Bowers (1997) offer a specific mechanism through which naming deficits might contribute separately to reading difficulties. They propose that children who are slow at naming printed symbols may have trouble reading because they are not activating the visual and phonological codes for the printed letters in memory close enough in time to encode the letter combinations that occur frequently in print. Hence they do not build up their knowledge of orthographic patterns of words as quickly as children with faster letter identification skills. However, a majority of the studies that have addressed the impact of naming on reading achievement, have been performed by Englishspeaking children in school age. Often the participants have been children with reading difficulties. For example, the double deficit theory by Wolf and Bower (1997) claims that naming explains a separate and unique contribution of the variance in reading achievement in addition to the variance caused by skills in phonological awareness. In our study we also addressed to what extent naming contributed to explain variance in early reading acquisition among kindergarten children using a highly consistent orthography.

A third enabling skill that has been considered important for reading acquisition is shortterm memory. Scarborough (1998) refers to eleven studies that report moderate and significant correlations between short-term memory and reading ability. Some studies have documented that short-term memory is not significantly related to reading when phonemic awareness is partialed out (Rohl \& Pratt 1995; Wagner, Torgesen \& Rashotte 1994). Most of these studies have a predictive design, where the impact of short-term memory on later reading performance has been investigated. Furthermore, a majority of these studies are performed in language with deep or opaque orthography. It is therefore important using transparent orthographies when studying the relationship between various enabling skills and reading achievement (Frost 1993). Therefore, our kindergarten study examined if short-term memory accounted for unique variance in reading tasks among Latvian children.

Although many different enabling skills have been shown to correlate with reading performance, relatively little attention has been paid to the question of the relationships among these tasks. Wagner, Torgesen, Laughon, Simmons and Rashotte (1993) have conducted sophisticated studies of the factorial structure of phonological abilities. Their focus was on testing the differentiability of phonological awareness, phonological memory, and 
rapid naming skills. In the present study a similar research design is applied when studying the impact of phonological skills on early reading acquisition.

In sum, the goal of the present study was to examine the interrelationships among different enabling skills among children in Latvian kindergartens, and consider how various enabling skills contribute to explain unique variance in early reading acquisition.

\section{Method}

Subjects

A total of 76 children ( 40 girls and 36 boys) participated in the study. The children were randomly selected from four different kindergartens in the city of Riga. They ranged in age from 6 to 7 years with an average of 6 years, 4 months, $(\mathrm{SD}=4.4$ months). All parents who were approached agreed to participate in the study.

The children's parents or guardians were asked to complete a questionnaire about the linguistic situation at home, the native language of the family, whether the child had ever lived for a long period of time in a different linguistic environment or whether foreign language speakers were living under the same roof as the child, etc. Only children from mono-linguistic Latvian-speaking families were included in the study.

The Latvian language was also the only language used in the kindergartens participating in the present study. In Latvia, kindergarten children usually get formal instruction in enabling skills, for example, letter recognition, letter-sound correspondences and sound blending. Although the practice may vary somewhat from kindergarten to kindergarten, it is not uncommon that some instruction in word recognition is also given.

Tests

The tests in the present study included both phonological enabling skills and various reading abilities. The following tests were employed to assess enabling skills: rhyming, syllable counting, phoneme deletion, phoneme isolation, phoneme segmentation, rapid naming, and 
verbal short-term memory. The reading tests included word and sentence reading. In addition, a test of letter knowledge was given.

Rhyming: The child's task was to select the word among the three alternatives that rhymed with the target word. The test had two practice words with feedback support and 20 experimental words without feedback support. The experimenter first pronounced a target word, and then the three test words. The words varied in length (1 or 2 syllables), and all of them were well known for the children. There were 20 rhymes in the test, 3 one-syllable words and 17 two-syllables words. Nine of the words had CVCV structure, whereas the other words had structures such as CVCC, CVCVC, CCVCV, CVCCV, and CVVCC. (The rhymeelement in each word is underlined.) The performance score was the total number of correctly chosen rhyme words.

Syllable counting: The syllable counting test consisted of two practice words with feedback support and 20 experimental words without feedback support. In the practice tasks, the experimenter pronounced the target word by specially stressing each syllable, while in the experimental tasks the words were pronounced in the normal way, without particular stress on the individual syllables. The task was to count the number of syllables in each orally presented word. The number of syllables varied from 1 to 4 , with a mixed difficulty throughout the test. (There were 1 word with only one syllable, 10 words with 2 syllables, 6 words with 3, and 3 words with 4 syllables.) In Latvian, the stress is usually put on the first syllable. The performance score was the total number of words where the student gave the correct number of syllables.

Three tests were used to assess phonemic awareness: phoneme deletion, phoneme isolation, and phoneme segmentation.

Phoneme deletion: This test assessed the child's ability to identify and delete the first or the last phoneme of the target word and provide the pronunciation of the word or nonword remaining after this deletion. The target phonemes were consonants in 17 of the test items and vowels in 3 items. The test had two practice items with feedback support and 20 experimental items without feedback. The words varied in length from 3 to 10 phonemes (mostly onesyllable and two-syllables words), and all of them were selected from the vocabulary used by children at this age. Experienced preschool teachers constructed the word list based on their thorough knowledge of the typical vocabulary of kindergarten children at this age. For the first half of the items, the children were asked to delete the initial phoneme; for the second half, they had to delete the final phoneme. In 7 test items the phoneme deletion produced a word, whereas in 13 test items the correct answer was a pronounceable nonword. The target 
phonemes to be deleted were in most cases consonants, but in a few test items the final phoneme was a vowel. The performance score was the total score of correct responses.

Phoneme isolation: In the phoneme isolation test the child had to isolate and produce correctly the first or the last sound of a well-known word that was presented orally by the experimenter. A majority of the target phonemes were consonant-sounds. The test had two practice trials with feedback support and 20 experimental words without feedback. The words varied in length from 3 to 10 letters (2-3 syllables) and were presented in random order. In a few cases the onset of the target word consisted of two consonants, and the task was to delete the first one. Some of the words ended in diphthongs, which the child had to isolate. The performance score was the total number of words in which the child correctly pronounced the phoneme.

Phoneme segmentation: The phoneme segmentation test assessed the child's ability to identify phonemes in orally presented words. The test included two practice items with feedback support, and 20 experimental items without feedback. The words varied from short and phonologically simple words at the beginning of the test to longer and phonologically complex words at the end (from 4 to 9 phonemes). All words were a part of the children's receptive vocabulary. The experimenter read the word aloud with normal speed and articulation. The children had to segment the word into its constituent phonemes and provide the sounds aloud. The performance score was the number of words segmented correctly.

Two subtests were used to assess rapid naming: Object naming and color naming.

Object naming: This test was used to assess the child's ability to retrieve the phonological representation of words presented as drawings on a sheet of paper. Five familiar objects were depicted: an apple, a house, a tree, a sun, and a star. The drawings of each object occurred several times in random order on the sheet (total number of pictures on the sheet was 180). Time limit was 1 minute. The child got a practice task with feedback response showing all five drawings. The performance score was the total number of objects named correctly during the testing time.

Color naming: This subtest was similar to object naming, but instead of naming objects, the task here was to name colors. The task consisted of 5 colors: black, green, blue, red, and yellow, which occurred several times in random order on a sheet of paper (total number of items on the sheet was 180). The child got a practice task with feedback for all five colors. The performance score was the number of times the child correctly called out the name of the color. Test time was 1 minute.

Verbal-short term memory was assessed by a digit-span test and by a letter-span test. 
Repeating digits: The Digit Span subtest of the Wechsler Intelligence Scale for Children Revised (WISC-R; Wechsler 1974) was used to assess memory for digits. The strings of digits were presented orally with about $1 / 2$ second between each digit. The child had to repeat the digits in each string in correct order. The strings started with only two digits, and one digit was added for each new digit string. The test continued until the child made a mistake on two subsequent strings. The child got two practice examples with feedback support before the test items were presented, but otherwise no feedback was given. The performance score was the number of digits in the longest string repeated correctly.

Repeating letters: This test was similar to the digit-naming test, but instead of digits, strings of letters were used. Again, two practice examples with feedback support were provided before presenting the letter strings. The performance score was the number of letters in the longest string repeated correctly.

Letter reading: The child was presented with 45 letters, including both upper and lower case. The Latvian alphabet consists of 33 letters ( 9 vowels and 24 consonants) and is based on the Latin alphabet. There are four long vowels and seven soft consonants, and in writing they are marked with a special sign. The letters were presented on a sheet of paper in a 12-point font (Times New Roman). Two practice trials with feedback support were provided. The performance score was the total number of letters named correctly.

Word reading: The task was to read a series of 60 experimental words aloud. The words varied in length (from 2 to 15 letters), number of syllables (from 1 to 8 syllables), and in phonological/orthographic complexity. Most of the words were 2 to 4 syllables, and only 1 was 8 syllables long. All words were written on a sheet of paper and presented in a 12-point font (Times New Roman). The performance score was the number of words correctly read.

Sentence reading: The child was presented with two practice sentences and 60 experimental sentences with five pictures below each sentence. The task was to read each sentence and choose the one of the five alternative pictures that corresponded to the target sentence. Feedback support was given on the two practice sentences. During the experimental tasks, however, no feedback was provided. The time limit for this test was 10 minutes. The sentences used varied in length and syntactical structure, and they were all in active form. In the study, sentence reading was used as a simple measure of reading comprehension. However, it has to be recognised that reading single sentences cannot measure the complex processes involved when reading and interpreting paragraphs of texts. Sentence reading only assesses elementary reading comprehension processes, and this limitation has to be taken into 
account when interpreting the results in the present study. The performance score was the total number of pictures correctly marked.

\section{Procedure}

The tests were administered to the children individually by trained research assistants. The tests were carried out during two weeks in May and included two or three test sessions for each child. In order to provide optimal testing conditions, no session exceeded a time limit of 30 minutes.

The test results were recorded on specially prepared scoring sheets, where the research assistants only were required to mark each child's response. Each assistant did the scoring individually in accordance with a clear description of how to score the different tests. All scoring was checked by one of the researchers responsible for the study.

\section{Results}

\section{Descriptive statistics}

Table 1 presents the means, standard deviations, maximum scores, ranges, and skewness for all variables used in the present study.

One of the tasks, phoneme isolation, was excluded in the further analysis due to high ceiling effect (skewness $=-2.61$ ). The other tasks discriminated well among the children.

Table 2 presents the correlations among all of the major variables in the study.

The phonemic tasks displayed significant, moderate inter-correlations. The mean correlation across these tasks was 0.55 . The correlations between the phonemic tasks and word and sentence reading were all moderately high and significant. It is noteworthy that the rhyme task correlated moderately with the two phonemic tasks, with a mean correlation of 0.38 across the phonemic tasks $(\mathrm{p}<.01)$. It should also be noted that rhyme correlated significantly with sentence reading $(r=0.448, p<.01)$, but not with word reading. Syllable counting, which was used as an indicator of syllable awareness, correlated significantly 
with object and color naming, but skill in syllable counting was not correlated to the reading tasks. Therefore, the syllable tasks were not included in the further analyses.

Table 1. Means, standard deviations and ranges for the measures of enabling skills and reading $\underline{\text { abilities }}$

\begin{tabular}{lllllc}
\hline Task & Mean & SD & Maximum & Range & Skewness \\
\hline Rhyming & 11.61 & 3.82 & 20 & 16 & 0.45 \\
Syllable counting & 11.73 & 5.66 & 20 & 20 & -0.57 \\
Phoneme deletion & 10.87 & 5.41 & 20 & 20 & -0.62 \\
Phoneme segmentation & 8.30 & 5.29 & 20 & 20 & 0.28 \\
Phoneme isolation & 17.51 & 2.93 & 20 & 18 & -2.61 \\
Object naming & 44.49 & 11.57 & 180 & 43 & -0.48 \\
Color naming & 46.94 & 11.62 & 180 & 45 & 0.07 \\
Repeating digits & 3.94 & 1.29 & 9 & 5 & -1.07 \\
Repeating letters & 3.49 & 1.16 & 9 & 6 & -0.71 \\
Word reading & 37.87 & 19.26 & 60 & 57 & -1.09 \\
Sentence reading & 16.09 & 11.29 & 60 & 45 & 0.46 \\
\hline
\end{tabular}

The correlation between repeating digits and letters (the two short-term memory tasks) was high and significant $(\mathrm{r}=0.667, \mathrm{p}<.001)$, but only repeating digits correlated significantly with a reading task (sentence reading: $r=0.411, \mathrm{p}<.01$ ). The highest correlation was found between object and color naming $(r=0.846, p<.001)$, and color naming also correlated significantly with sentence reading $(r=0.335, \mathrm{p}<.01)$. 
Table 2. Intercorrelations among kindergarten measures (Bonferroni corrected)

\begin{tabular}{|c|c|c|c|c|c|c|c|c|c|c|}
\hline Task & 1 & 2 & 3 & 4 & 5 & 6 & 7 & 8 & 9 & 10 \\
\hline 1. Rhyming & 1.000 & & & & & & & 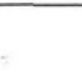 & & \\
\hline $\begin{array}{l}\text { 2. Syllable } \\
\text { counting }\end{array}$ & .219 & 1.000 & & & & & & & & \\
\hline $\begin{array}{l}\text { 3. Phoneme } \\
\text { deletion }\end{array}$ & $.340^{* *}$ & .070 & 1.000 & & & & & & & \\
\hline $\begin{array}{l}\text { 4. Phoneme } \\
\text { segmentation }\end{array}$ & $.423 * *$ & .073 & $.626^{* *}$ & 1.000 & & & & & & \\
\hline $\begin{array}{l}\text { 5. Object } \\
\text { naming }\end{array}$ & $.228^{*}$ & $.469^{* *}$ & $.364^{* *}$ & $.281^{*}$ & 1.000 & & & & & \\
\hline $\begin{array}{l}\text { 6. Color } \\
\text { naming }\end{array}$ & .239 & $.386^{* *}$ & $.405^{* *}$ & $.277^{*}$ & $.846^{* *}$ & 1.000 & & & & \\
\hline $\begin{array}{l}\text { 7. Repeating } \\
\text { digits }\end{array}$ & .216 & .127 & $.353^{* *}$ & $.422 * *$ & $.337^{* *}$ & $.432 * *$ & 1.000 & & & \\
\hline $\begin{array}{l}\text { 8. Repeating } \\
\text { letters }\end{array}$ & .151 & .094 & $.247^{*}$ & $.346^{* *}$ & $.344^{* *}$ & $.408^{* *}$ & $.667^{* *}$ & 1.000 & & \\
\hline 9. Word reading & .285 & .119 & $.566^{* * *}$ & $.563^{* * *}$ & .219 & .197 & .237 & .155 & 1.000 & \\
\hline $\begin{array}{l}\text { 10. Sentence } \\
\text { reading }\end{array}$ & $.448^{* *}$ & .016 & $.545^{* * *}$ & $.530^{* * *}$ & .230 & $.335^{* *}$ & $.411 * *$ & .203 & $.732 * * *$ & 1.000 \\
\hline
\end{tabular}

Note: Significance level of correlation (two tailed): ${ }^{*} \mathrm{p}<.05,{ }^{* *} \mathrm{p}<.01,{ }^{* * *} \mathrm{p}<.001$.

\section{Relationship between phonological skills and reading}

One way to conceptualize the relationships among phonological tasks is in terms of factor analysis. A principal component analysis (rotated, varimax) yielded 3 factors with eigenvalues greater than one. The results are displayed in Table 3.

Altogether the three factors explained about $70 \%$ of the total variance. The first principal component accounted for $40 \%$ of the variance, with the naming tasks loading on this component. The second component accounted for $16.7 \%$ of the variance, and the two phonemic awareness tasks loaded highest on this factor. As expected from the correlation analysis, the rhyme task also loaded highly on this factor. 
Table 3. Principal components loadings for all enabling variabies

\begin{tabular}{llll}
\hline Variables & Naming & $\begin{array}{l}\text { Phonemic } \\
\text { awareness }\end{array}$ & Memory \\
\hline Total variance explained & $40.0 \%$ & $16.7 \%$ & $13.0 \%$ \\
\hline Rhyming & 0.252 & 0.659 & 0.061 \\
Syllable counting & 0.757 & 0.162 & 0.048 \\
Phoneme deletion & 0.221 & 0.678 & 0.228 \\
Phoneme segmentation & 0.096 & 0.754 & 0.425 \\
Phoneme isolation & 0.076 & 0.778 & 0.024 \\
Object naming & 0.863 & 0.129 & 0.282 \\
Color naming & 0.816 & 0.117 & 0.372 \\
Repeating digits & 0.175 & 0.216 & 0.844 \\
Repeating letters & 0.204 & 0.046 & 0.868 \\
\hline
\end{tabular}

Finally, the third component explained $13 \%$ of the variance, and the two memory tasks loaded highly on this component. The syllable task also loaded high on this factor, but the results on the correlation analysis showed that the syllable task was only moderately correlated with the naming tasks, compared with the high correlation between the two naming tasks.

Three composite scores were constructed to be used in the hierarchial regression analyses: The composite score for naming was constructed by summing the standardized scores on color and object naming. Likewise, the composite score for phonemic awareness was constructed by summing the standardized score on phoneme segmentation and phoneme deletion. Finally, the standardized scores on digit and letter repeating yielded a composite score for short-term memory.

A series of hierarchical regression analyses were conducted in order to explore the impact of the various independent variables on word and sentence reading ability.

In the first series of hierarchical regression analyses, word reading was used as dependent variable, with age, phonemic awareness, naming, and memory as independent variables. The results are presented in Table 4.

The analysis revealed that phonemic awareness accounted significantly for $14.2 \%$ of unique variance $(\mathrm{p}<.001)$. Neither naming nor short-term memory contributed to explain unique variance in word reading. 
Table 4. Unique variance in word reading explained by phonological skills

Unique variance in word reading explained by phonemic awareness after partialing out age, memory, and naming

\begin{tabular}{lllll}
\hline Step & Variable & $\mathrm{R}^{2}$ & $\mathrm{R}^{2}$ change & $\mathrm{F}$ \\
\hline 1. & Age & 0.036 & 0.036 & $2.304 \mathrm{~ns}$. \\
2. & Memory & 0.168 & 0.132 & $9.712^{* *}$ \\
3. & Naming & 0.228 & 0.060 & $7.664^{* *}$ \\
4. & Phonemic awareness & 0.365 & 0.142 & $12.708^{* * *}$ \\
\hline
\end{tabular}

Unique variance in word reading explained by memory after partialing out age, phonemic awareness, and naming

\begin{tabular}{lllll}
\hline Step & Variable & $\mathrm{R}^{2}$ & $\mathrm{R}^{2}$ change & $\mathrm{F}$ \\
\hline 1. & Age & 0.036 & 0.036 & $2.308 \mathrm{~ns}$. \\
2. & Phonemic awareness & 0.307 & 0.271 & $23.907^{* * *}$ \\
3. & Naming & 0.335 & 0.028 & $2.456 \mathrm{~ns}$. \\
4. & Memory & 0.365 & 0.030 & $2.804 \mathrm{~ns}$. \\
\hline
\end{tabular}

Unique variance in word reading predicted by naming after partialing after age, phonemic awareness, and memory

\begin{tabular}{lllll}
\hline Step & Variable & $\mathrm{R}^{2}$ & $\mathrm{R}^{2}$ change & $\mathrm{F}$ \\
\hline 1. & Age & 0.036 & 0.036 & $2.304 \mathrm{~ns}$. \\
2. & Phonemic awareness & 0.307 & 0.271 & $23.907 * * *$ \\
3. & Memory & 0.342 & 0.035 & $3.202 \mathrm{~ns}$. \\
4. & Naming & 0.365 & 0.023 & $2.074 \mathrm{~ns}$ \\
\hline
\end{tabular}

Note: ${ }^{* *} \mathrm{p}<.01,{ }^{* * *} \mathrm{p}<.001, \mathrm{~ns} .=$ not significant

In the second series of hierarchical regression analyses, letter knowledge was also entered into the equation as an independent variable. Our main interest was to investigate the impact of letter knowledge on word reading, and how much unique variance phonemic awareness could explain when controlling for age, letter knowledge, memory, and naming. The results are displayed in Table 5 . 
Table 5. Unique variance in word reading explained by phonemic awareness and letter knowledge

Unique variance in word reading explained by phonemic awareness after partialing out age, letter knowledge, memory, and naming

\begin{tabular}{lllll}
\hline Step & Variable & $\mathrm{R}^{2}$ & $\mathrm{R}^{2}$ change & $\mathrm{F}$ \\
\hline 1. & Age & 0.071 & 0.071 & $0.018 \mathrm{~ns}$. \\
2. & Letter knowledge & 0.656 & 0.585 & $111.620^{* * *}$ \\
3. & Memory & 0.676 & 0.020 & $3.649 \mathrm{~ns}$. \\
4. & Naming & 0.687 & 0.011 & $2.164 \mathrm{~ns}$. \\
5. & Phonemic awareness & 0.727 & 0.040 & $8.363^{* *}$ \\
\hline
\end{tabular}

Unique variance in word reading explained by letter knowledge after partialing out age, phonemic awareness, memory, and naming

\begin{tabular}{lllll}
\hline Step & Variable & $\mathrm{R}^{2}$ & $\mathrm{R}^{2}$ change & $\mathrm{F}$ \\
\hline 1. & Age & 0.071 & 0.071 & $0.018 \mathrm{~ns}$. \\
2. & Phonemic awareness & 0.336 & 0.265 & $8.363^{* *}$ \\
3. & Memory & 0.336 & 0.000 & $0.086 \mathrm{~ns}$. \\
4. & Naming & 0.340 & 0.004 & $0.359 \mathrm{~ns}$. \\
5. & Letter knowledge & 0.727 & 0.387 & $81.865^{* * *}$ \\
\hline
\end{tabular}

Note: ${ }^{* *} \mathrm{p}<.01,{ }^{* * *} \mathrm{p}<.001, \mathrm{~ns} .=$ not significant

Phonemic awareness accounted for $4 \%$ of unique variance $(p<.001)$ in word reading, whereas letter knowledge accounted for $38.8 \%$ of unique variance when partialing out age, phonemic awareness, memory, and naming. Clearly letter knowledge is a more powerful factor than phonemic awareness when explaining variance in early reading acquisition. Surprisingly, neither the memory nor the naming variable accounted for unique variance in word reading.

In the third series hierarchical regression analysis, sentence reading was used as dependent variable. In order to investigate the contribution of the independent variables on sentences reading, a hierarchical regression analysis was performed with sentence reading as dependent variable, and with age, phonemic awareness, naming, short-term memory as independent variables. The results are displayed in Table 6. 
Table 6. Unique variance in sentence reading explained by phonological skills

Unique variance in sentence reading explained by phonemic awareness after partialing out age, memory, and naming

\begin{tabular}{lllll}
\hline Step & Variable & $\mathrm{R}^{2}$ & $\mathrm{R}^{2}$ change & $\mathrm{F}$ \\
\hline 1. & Age & 0.036 & 0.036 & $2.308 \mathrm{~ns}$. \\
2. & Memory & 0.168 & 0.132 & $9.712^{* *}$ \\
3. & Naming & 0.228 & 0.060 & $4.635^{*}$ \\
4. & Phonemic awareness & 0.365 & 13.700 & $12.708^{* * *}$ \\
\hline
\end{tabular}

Unique variance in sentence reading explained by memory after partialing out age, phonemic awareness, and naming

\begin{tabular}{lllll}
\hline Step & Variable & $\mathrm{R}^{2}$ & $\mathrm{R}^{2}$ change & $\mathrm{F}$ \\
\hline 1. & Age & 0.036 & 0.036 & $2.308 \mathrm{~ns}$. \\
2. & Phonemic awareness & 0.307 & 0.271 & $23.907^{* * *}$ \\
3. & Naming & 0.335 & 0.028 & $2.456 \mathrm{~ns}$. \\
4. & Memory & 0.365 & 0.003 & $2.804 \mathrm{~ns}$. \\
\hline
\end{tabular}

Unique variance in sentence reading explained by naming after partialing out age, phonemic awareness, and memory

\begin{tabular}{lllll}
\hline Step & Variable & $\mathrm{R}^{2}$ & $\mathrm{R}^{2}$ change & $\mathrm{F}$ \\
\hline 1. & Age & 0.036 & 0.036 & $2.308 \mathrm{~ns}$. \\
2. & Phonemic awareness & 0.307 & 0.271 & $23.907^{* * *}$ \\
3. & Memory & 0.342 & 0.035 & $3.202 \mathrm{~ns}$. \\
4. & Naming & 0.365 & 0.023 & $2.074 \mathrm{~ns}$ \\
\hline
\end{tabular}

Note: ${ }^{* *} \mathrm{p}<.01,{ }^{* * *} \mathrm{p}<.001, \mathrm{~ns} .=$ not significant

The hierarchical regression analysis demonstrated that phonemic awareness explained $13.7 \%$ of unique variance in sentence reading. Neither memory nor naming contributed to explain unique variance in sentence reading. 


\section{Discussion}

In the present study a principal component analysis was performed to address the issue of the structure and distinctness of phonological and other enabling skills. A broad array of measures to investigate potential factors in reading acquisition was included in the study.

The principal component analysis yielded three separate factors: a phonemic awareness factor, a naming factor and a verbal short-term memory factor. Our results do not support Bentin's (1992) hypothesis about two qualitatively different forms of phonological awareness, one characterized by rhyme awareness and skill in syllable segmentation, and the other characterized by phonemic awareness. In our study the rhyme task loaded high on the same factor as the phonemic awareness tasks.

It is noteworthy that syllable awareness loaded high on the naming factor. As far as we know, similar results have not been reported previously. The mechanisms underlying these results are not clear, and further research is needed to explore this relationship. It might be the case that task-specific factors have biased our results.

The results on the series of hierarchical regression analyses provided information about how the various enabling skills contributed to explain unique variance on reading tasks.

One main finding in our study was the unique impact of phonemic awareness on early reading acquisition. Our results thus add further support to the abundance of research documenting how closely related phonemic awareness is to reading achievement (Adams 1990; Bruck 1990, 1992; Høien, Lundberg, Stanovich \& Bjaalid 1995; Liberman \& Shankweiler 1991; Lundberg \& Høien 1989; Manis, Custodio \& Szeszulski 1993; Olson, Wise, Conners \& Rack 1990; Pennington, van Orden, Smith, Green \& Haith 1990; Rack, Snowling \& Olson 1992; Siegel 1989; Stanovich 1992; Wagner \& Torgesen 1987). Phonemic awareness explained uniquely about 14 per cent of the variance in word reading and about 14 per cent of the variance in sentence reading, which shows that phonemic awareness is important for reading achievement also in a highly consistent language as Latvian.

Our results give evidence to findings reported by Müller and Brady (2001). Using hierarchical regression analysis they found that even for a transparent language as Finnish phonemic awareness assessed in kindergarten still accounted for noteworthy percentage of variance in word accuracy and reading comprehension at the end of grade.

Correlation figures cannot tell anything about causal relationship, but longitudinal studies have documented that phonemic awareness is an important prerequisite for learning to read 
(Cunningham 1990; Lundberg, Frost \& Petersen 1988; McGuiness, McGuiness \& Donohue 1995; Schneider, Kuspert, Roth, Mechtild \& Marx 1977). Therefore, early phonemic awareness training should be recommended for kindergarten in general and for at-risk children especially. There is now an extensive research base that supports the effectiveness and practical utility of providing kindergarten children with instruction in phonological awareness.

Another important finding in our study was the clear demonstration of the power of letter knowledge to explain variance in early reading acquisition. Letter knowledge explained onethird of the variance in word reading (see also Frost 2001). Furthermore, the hierarchical regression analyses showed that phonemic awareness and letter knowledge make separate and specific contributions to beginning literacy. Our results give additional support to earlier research findings (for overview, see Snow, Burns \& Griffin 1998). Byrne and FieldingBarnsley (1989), for example, reported that letter knowledge accounted for more variance in word decoding tasks than measures of phonemic awareness. Similar findings are also reported by Muter, Hulme, Snowling and Taylor (1998) and Gallagher, Frith and Snowling (2000). Obviously letter knowledge is important whatever orthography is used. The combination of phonemic awareness and letter knowledge, termed "phonological linkage" by Hatcher, Hulme and Ellis (1994), is clearly the most critical factor when addressing reading acquisition (Muter 2000).

It was somewhat surprising that we could not find any significant relationship between rapid naming and early reading skills. Scarborough's (1998) review of longitudinal studies indicated that rapid naming was at least as strongly related to later reading skills such as letter name knowledge and phonological awareness. However, our participants were children in kindergarten. Among older children the relationship may be different. This is in accordance with findings by Pennington, Cardoso-Martins, Green and Lefly (2001). These researchers found that rapid serial naming was less powerful to explain variance in reading skills than did phonemic awareness. They reported that variation in rapid serial naming was particularly important for fluent text reading, whereas phonemic awareness was important for development of the ability to read. Therefore, it seems reasonable to assume that naming is more related to reading at later stages in reading development, for example when the reader is using an orthographic decoding strategy (see also Wolf 2001).

We had also expected that verbal short-term memory would have power to explain variance both in word and sentence reading. The results on the hierarchical regression analyses did not provide evidence for this expectation. Several studies have reported 
significant correlations between verbal short-term memory. Hanson and Bowey (1994) in a study among 7-year olds found that both phonemic awareness and verbal memory accounted for unique variance on three reading measures. We may wonder why we did not get the same results. The disparate results reported in the various studies may partly be caused by the method and statistical methods employed. Often correlation analysis is the preferred method, but correlations do not provide information about the unique contribution of short-term memory on reading performance. Several phonological factors are correlated with memory. In order to estimate the unique contribution of short-term memory on reading tasks, other statistical methods have to be used as, for example, hierarchical regression analysis or structural modeling. Further research studies are needed to clarify the role played by shortterm memory in explaining variance in early reading acquisition.

In sum, phonemic awareness seems to be the paramount skill related to reading achievement, even in a highly consistent language such as Latvian; and together with letter knowledge it represents the most powerful factor for explaining variance in early reading acquisition. We agree with Byrne and Fielding-Barnsley (1989) that enhancing children's phonemic awareness and letter knowledge skills should be a priority in the kindergarten classroom.

\section{Acknowledgements}

This research was supported by grants from the Faculty of Psychology, University of Bergen, the Nordic Research Council and The Dyslexia Research Foundation, Stavanger, Norway.

\section{References}

Adams, M. (1990). Beginning to read: Thinking and learning about print. Cambridge, MA: MIT Press.

Baddeley, A. (1986). Working memory. New York: Oxford University Press.

Badian, N. (ed.) (2000). Prediction and prevention of reading failure. Baltimore, Maryland: York Press. 
Bentin, S. (1992). Phonological awareness, reading and reading acquisition: A survey and appraisal of current knowledge. In R. Frost \& L. Katz (eds.), Orthography, phonology, morphology, and meaning (pp. 193-210). Amsterdam: North-Holland.

Blachman, B. (ed.). (1997). Foundations of reading acquisition and dyslexia, implications for early intervention. Mahwah, $\mathrm{NJ}$ : Erlbaum.

Brady, S. (1997). Ability to encode phonological representations: An underlying difficulty of poor readers. In B. Blachman (ed.), Foundations of reading acquisition and dyslexia. Implications for early intervention (pp. 21-47). Mahwah, NJ: Erlbaum.

Bruck, M. (1990). Word-recognizition skills of adults with childhood diagnoses of dyslexia. Developmental psychology 26: 439-454.

Bruck, M. (1992). Persistance of dyslexics' phonological awareness deficits. Developmental Psychology 28: 874-886.

Byrne, B. \& Fielding-Barnsley, R. (1989). Phonemic awareness and letter knowledge in the child's acquisition of the alphabetic principle. Journal of Educational Psychology 82: 805-812.

Cossu, G., Shankweiler, D., Liberman, A. \& Gugliotta, J.T. (1995). Visual and phonological determinants of misreadings in a transparent orthography. Reading and Writing: An Interdisciplinary Journal 3: 237-256.

Cunningham, A. (1990). Explicit versus implicit instruction in phonemic awareness. Journal of Experimental Child Psychology 50: 429-444.

Cutting, L. \& Denckla, M. (2001). The relationship of rapid serial naming and word reading in normally developing readers: An exploratory model. Reading and Writing: An Interdisciplinary Journal 14: 673-705.

Frith, U. (1985). Beneath the surface of developmental dyslexia. In K. Patterson, J. Marshall \& M. Coltheart (eds.), Surface dyslexia: Neuropsychological and cognitive studies of phonological reading (pp. 301-330). London: Erlbaum.

Frost, J. (1993). Prelexical and postlexical strategies in reading: Evidence from a deep and shallow orthography. Haskins Laboratories Status Report on Speech Research SR 113: 153-170.

Frost, J. (2001). Differences in reading development among Danish beginning-readers with high versus low phonemic awareness on entering grade one. Reading and Writing: An Interdisciplinary Journal 14: 487-513.

Gallagher, A., Frith, U. \& Snowling, M. (2000). Precursors of literacy delay among children at risk of dyslexia. Journal of Child Psychology and Psychiatry 41: 203-213. 
Hanson, J. \& Bowey, J. (1994). Phonological analysis skills, verbal working memory and reading ability in second grade children. Child Development 65: 938-950.

Hatcher, P., Hulme, C. \& Ellis, A. (1994). Ameliorating early reading failure by integrating the teaching of reading and phonological skills: The phonological linkage hypothesis. Child Development 65: 41-57.

Høien, T. \& Lundberg, I. (1988). Stages of word recognition in early reading acquisition. Scandinavian Journal of Educational Research 32: 163-182.

Høien, T., Lundberg, I., Stanovich, K. \& Bjaalid, I. (1995). Components of phonological awareness. Reading and Writing: An Interdisciplinary Journal 7: 1-18.

Landerl, K., Wimmer, H. \& Frith, U. (1997). The impact of orthographic consistency on dyslexia: A German-English comparison. Cognition 3: 315-334.

Liberman, I. \& Shankweiler, D. (1991). Phonology and beginning to reading: A tutorial. In L. Rieben \& C. Perfetti (eds.), Learning to read: Basic research and its implications (pp.317). Hillsdale, NJ: Erlbaum.

Lundberg, I. \& Høien, T. (1989). Phonemic deficits - a core symptom of developmental dyslexia? The Irish Journal of Psychology 10: 579-592.

Lundberg, I., Frost, J. \& Petersen, O. (1988). Long term effects of a preschool training program in phonological awareness. Reading Research Quarterly 28: 263-284.

Manis, F., Custodio, R. \& Szeszulski, P. (1993). Development of phonological and orthographic skill: A 2-year longitudinal study of dyslexic children. Journal of Experimental Child Psychology 56: 64-86.

McGuiness, D., McGuiness, C. \& Donohue, J. (1995). Phonological training and the alphabet principle: Evidence for reciprocal causality. Reading Research Quarterly 30: 830-852.

Muter, V. (2000). Screening for early reading failure. In N. Badian (ed.), Prediction and prevention of reading failure (pp. 1-29). Baltimore, Maryland: York Press.

Muter, V. \& Snowling, M. (1998). Concurrent and longitudinal predictors of reading: The role of metalinguistic and short-term memory skills. Reading Research Quarterly 33: 320337.

Muter, V., Hulme, C., Snowling, M. \& Taylor, S. (1998). Segmentation, not rhyming predicts early progress in learning to read. Journal of Experimental Child Psychology 71: 3-27.

Müller, K. \& Brady, S. (2001). Correlates of early reading performance in a transparent orthography. Reading and Writing: An Interdisciplinary Journal 14: 757-799.

Olson, R., Wise, B., Conners, F. \& Rack, J. (1990). Organization, heritability, and remediation of component word recognition and language skills in disabled readers. In $\mathrm{T}$. 
Carr \& B. Levy (eds.), Reading and its development: Component skills approaches (pp. 261-322). New York: Academic Press.

Pennington, B., Cardoso-Martins, C., Green, P. \& Lefly, D. (2001). Comparing the phonological and double deficit hypotheses for developmental dyslexia. Reading and Writing: An Interdisciplinary Journal 14: 707-755.

Pennington, B., van Orden, G., Smith, S., Green, P. \& Haith, M. (1990). Phonological processing skills and deficits in adult dyslexics. Child Development 61: 1001-1013.

Rack, J., Snowling, M. \& Olson, R. (1992). The nonword reading deficit in developmental dyslexia: A review. Reading Research Quarterly 27: 28-53.

Rohl, M. \& Pratt, C. (1995). Phonological awareness, verbal working memory and acquisition of literacy. Reading and Writing 7: 327-360.

Scarborough, H. (1998). Early identification of children at risk for reading disabilities: Phonological awareness and some other promising predictors. In B. Shapiro, P. Accardo \& A. Capute (eds.), Specific Reading Disability: A View of the Spectrum (pp. 77-121). Timonium: MD: York Press.

Schneider, W., Kuspert, P., Roth, H., Mechtild, V. \& Marx, H. (1977). Short- and long-term effects of training phonological awareness in kindergarten: Evidence from two German studies. Journal of Experimental Child Psychology 66: 311-340.

Share, D. (1995). Phonological recoding and self-teaching: Sine qua non of reading acquisition. Cognition 55: 151-218.

Siegel, L. (1989). IQ is irrelevant to the definition of learning disabilities. Journal of Learning Disabilities 22: 469-479.

Snow,C., Burns, M. \& Griffin, P. (eds.) (1998). Preventing reading difficulties in young children. Washington DC: National Academy Press.

Stanovich, K. (1992). Speculations on the causes and consequences of individual differences in early reading acquisition. In P. Gough, L. Ehri \& R. Treiman (eds.), Reading Acquisition (pp. 307-342). Hillsdale, NJ: Erlbaum.

Stanovich, K. (2000). Progress in understanding reading. Scientific foundations and new frontiers. New York: The Guildford Press.

Wagner, R. \& Torgesen, J. (1987). The nature of phonological processing and its causal role in the acquisition of reading skills. Psychological Bulletin 101: 192-212.

Wagner, R., Torgesen, J. \& Rashotte, C. (1994). The development of reading-related phonological processing abilities: New evidence of bi-directional causality from a latent variable longitudinal study. Development Psychology 30: 73-87. 
Wagner, R., Torgesen, J., Laughon, P., Simmons, K. \& Rashotte, C. (1993). Development of young readers' phonological processing abilities. Journal of Educational Psychology 85: 83-103.

Wagner, R., Torgesen, J., Rashotte, C., Hecht, S., Barker, T., Burgess, S., Donahue, J. \& Garon, T. (1997). Changing relations between phonological processing abilities and wordlevel reading as children develop from beginning to skilled readers: A 5-year longitudinal study. Developmental Psychology 33: 468-479.

Wechsler, D. (1974). Wechsler intelligence scale for children - revised. San Antonio, TX: Harcourt Brace, Jovanavich.

Wimmer, H. (1993). Characteristics of developmental dyslexia in a regular writing system. Applied Psycholinguistics 14: 1-33.

Wimmer, H., \& Goswami, U. (1994). The influence of orthographic consistency on reading development: Word recognition in English and German children. Cognition 51: 91-103.

Wimmer, J. \& Landerl, K. (1997). How learning to spell German differs from learning to spell English. In C. Perfetti \& L. Rieben (eds.), Learning to spell: Research, theory, and practice across languages (pp. 81-96). Mahwah, NJ: Erlbaum.

Wolf, M. (ed.) (2001). Dyslexia, fluency, and the brain. Timonium, Maryland: York Press.

Wolf, M. \& Bowers, P. (1997). The double-deficit hypothesis for the developmental dyslexias. Manuscript submitted for publication. 


\title{
Report II
}

\section{Early phonological skills and how they predict reading acquisition:}

\section{A follow-up study from kindergarten to the middle of grade 2}

\author{
IEVA SPRUGEVICA \\ University of Latvia, Riga, Latvia
}

\section{TORLEIV HØIEN}

Dyslexia Research Foundation, Stavanger, Norway

\begin{abstract}
The purpose of this study was to investigate the power of early measures of phonological skills (phonemic awareness, rapid naming, short-term memory) in predicting later reading skills at various points of time. About 70 children were followed from the end of kindergarten till the middle of $2^{\text {nd }}$ grade. Correlation analyses were performed as well as a linear growth curve analyses. In the traditional regression analysis, phonemic awareness in kindergarten explained about $27 \%$ of the variance in word reading six months later and about $9 \%$ of the variance at the end of $1^{\text {st }}$ grade. Even when prior level of reading skill was included in the predictive equation, a significant amount of variance was still explained by phonemic awareness. The other predictor variables did not explain any variance in word reading, and phonemic awareness did not predict any variance in reading skills in $2^{\text {nd }}$ grade. When using sentence reading as the dependent variable, phonemic awareness explained about $16 \%$ of unique variance after six months, and about $13 \%$ of the variance in the middle of $2^{\text {nd }}$ grade. Similarly, when employing growth curve analysis, phonemic awareness was the only phonological factor that accounted for significant variance in the word reading slope, explaining about $15 \%$ of the variance in the word reading slope, whereas naming and shortterm memory did not explain any unique variance. The lack of predictive power of phonemic awareness on the sentence b-slope is assumed to be caused by unreliable sentence scores in Kindergarten.
\end{abstract}

Key words: Growth-curve analysis, phonemic awareness, verbal short-term memory, naming, word reading, sentence reading. 


\section{INTRODUCTION}

During recent years there has been much focus on early intervention to prevent children who are at risk from becoming reading disabled. Teaching children to read before grade 3 has become a high-priority aim of current educational policy. Therefore, early identification of children who are likely to have reading problems constitutes the first step in preventing these problems (Blachman, 1994; Lundberg, Frost, \& Petersen, 1988; Santa \& Høien, 1999). This early-help approach has valid support in current reading research (for a review, see Snow et al., 1998). As a consequence of this research, more attention has been directed to early screening of children to find those who may be in the risk group. From a teaching standpoint, identifying these children as early as possible is clearly the best way to help them. The efficacy of such screening tests depends crucially on their validity at predicting later reading performance.

The prediction of success or failure in reading acquisition based on early assessments of pre-reading skills has been at the focus of interest in many studies (for a review, see Snow, Burns, \& Griffin, 1998). There is now a substantial body of evidence indicating that phonological skills, and especially phonological awareness, is one of the best predictors of the speed with which children acquire reading accuracy and fluency (Adams \& Bruck, 1995; Blachman, 1984; Lundberg, Olofsson, \& Wall, 1980; Stanovich, Cunningham, \& Cramer, 1984). Even when variance in prior word reading skill is partialed out, early phonological awareness still predicts significant variance in subsequent word and nonword reading ability as well as in reading comprehension (Torgesen, Wagner, \& Rashotte, 1997).

There is also evidence that other cognitive-linguistic skills, such as rapid naming and short-term memory, predict reading achievement (e.g., Badian, 1994, 1995, 2000; Bowers, 1995; Catts, 1993; Scanlon \& Vellutino, 1997). Rapid automatized naming seems to involve several sub-skills of critical importance for reading. In addition to an executive control function or attention control and visual processing, there is undoubtedly a phonological component (Bowers \& Wolf, 1993). In a study controlling for variance in initial reading ability (the auto-regressive effect), however, rapid naming did not turn out to predict any unique variance in reading performance (Torgesen, Wagner, Rashotte, Burgess, \& Hecht, 1997).

The child's ability to memorize and repeat verbal information has also been used as predictor of reading achievement. It is well known that reading ability and short-term memory are significantly correlated (for reviews, see Baddeley, 1986; Wagner \& Torgesen, 1987), and 
Scarborough (1998) also refers to several studies showing that verbal short-term memory significantly predicts later reading ability.

A practical limitation in many recent follow-up studies has been the tendency to use word decoding as the dependent variable rather than reading comprehension (e.g., Wagner, Torgesen, \& Rashotte, 1994). The ultimate aim of reading instruction is, of course, reading comprehension; but clearly, efficient word decoding is a necessary prerequisite for achieving this aim. The relative impact of early predictors, then, will differ depending on which predictor is being looked at and which aspect of reading is being predicted.

When investigating the impact of early predictors on later reading achievement, most studies have used traditional correlation analyses (Hecht, Burgess, Torgesen, Wagner, \& Rashotte, 2000; O'Connor \& Jenkins, 1999). Some studies, however, have addressed the relationship between early predictors and the growth curve characterizing the reading development (Olson, Wise, Johnson, \& Ring, 1997; Torgesen et al., 1997). Growth-curve analysis provides information about the parameters of the best fitting curve of individual reading development, such as the linear slope. By further statistical analyses, for example hierarchic regression analysis, the individual slope values can be used as a dependent variable when studying which predictor factors are most powerful in explaining the growth of reading development.

In the present study we have restricted the time window to the early and critical period of reading acquisition from the end of preschool to the middle of grade 2 with four occasions of measurement. Children's reading performance, including both word recognition and comprehension, was assessed four times at regular intervals from kindergarten to grade 2 . The time covered by the current study is certainly the most critical and important period for reading development (for a review, see Snow et al., 1998).

The aim of the current study was thus to examine the impact of early measures of phonological skills (phonemic awareness, rapid naming, short-term memory) in predicting later reading skills at various point in time. Based on previous research and theoretical considerations, these skills were assumed to be of critical importance for reading development. We also compared the more traditional approach used in predicting reading skills with the predictive power provided by applying the method of growth curve analysis. Moreover, our study of the prediction issue took place in Latvian. Latvian is a language with a far more regular orthography than English. 


\section{METHOD}

\section{Subjects}

The initial sample consisted of 70 kindergarten children, 39 girls and 31 boys, with an age range from 6 to 7 years $(\mathrm{M}=6$ years and 8 months, $\mathrm{SD}=4.4$ months $)$. The children were randomly selected from four different kindergartens in the city of Riga, and the first assessment was administered at the end of kindergarten (in May 2000). Only children from monolingual Latvian-speaking families were included in the study. The assessments were repeated twice a year (in May and in December) during a period of time covering 1.5 years. At the end of the study, only 53 of the original 70 children were still available for testing. However, the drop out of children seems to be rather random, caused primarily by parents moving to other cities in Latvia, which made it impossible to follow up these children with all four assessments.

In Latvia, kindergarten children usually get instruction in enabling skills, e.g. letter recognition, letter-sound correspondences and sound blending. Although the practice may vary somewhat from kindergarten to kindergarten, it is not uncommon that some instruction in word recognition is also given.

\section{Tests}

Two different types of tests were used in assessing the children. The predictor tests measured cognitive-linguistic abilities among children in kindergarten, while subsequent reading ability was assessed by tests of word decoding and reading comprehension at four different times during the follow-up study. The cognitive-linguistic tests included phonemic awareness tasks, rapid naming and verbal short-term memory. Additionally, the nonverbal cognitive level of some of the children was assessed. However, a too small proportion of children was assessed in this respect, so this part of the study was not included in the data analysis.

Two different tasks were used to assess phonemic awareness: phoneme segmentation and phoneme deletion. The phoneme segmentation test assessed the child's ability to identify phonemes in orally presented words. The test included two practice items with feedback support, and 20 experimental items without feedback. The words varied from short and 
phonologically regular words at the beginning of the test to longer and phonologically complex words at the end (from 4 to 9 phonemes). All words were a part of the children's receptive vocabulary. Experienced preschool teachers constructed the word list based on their thorough knowledge of the typical vocabulary of kindergarten children at this age. The experimenter read the word aloud with normal speed and articulation. The children had to segment the word into its constituent phonemes and provide the sounds aloud. The performance score was the number of words segmented correctly. The phoneme deletion test assessed the child's ability to identify and delete the first or the last phoneme of the target word and provide the pronunciation of the nonword remaining after this deletion. The test had two practice items with feedback support and 20 experimental items without feedback. The words varied in length from 3 to 10 phonemes, and all of them were selected from the vocabulary used by children at this age. For the first half of the items, the children were asked to delete the initial phoneme; for the half, they had to delete the final phoneme. The performance score was the total number of correct responses after deletion. In further statistical analyses the two phonemic scores were transformed into a composite score for phonemic awareness.

Two subtests were used to assess rapid naming. The object naming test assessed the child's ability to quickly retrieve the phonological representation of five familiar objects: an apple, a house, a tree, a sun, and a star. The drawings of each object occurred several times in random order on a sheet of paper (total number of pictures on the sheet was 80 ). The child was given a practice task with feedback for all five drawings before the real testing started. The performance score was the total number of objects named correctly during a testing time of one minute. The color naming test was similar to object naming, but instead of naming objects, the task here was to name colors. The test consisted of 5 color patches: black, green, blue, red, and yellow, which occurred several times in random order on a sheet of paper (total number of items on the sheet was 180). Each of the children got a practice task with feedback including all five colors before the test items were presented. The performance score was the total number of color patches the child correctly named during a testing time of one minute. In further statistical analyses the two test scores were transformed into a composite score for rapid naming.

Verbal short-term memory was assessed by a digit-span test and by a letter-span test. The strings of digits were presented orally with a time interval about 0.5 second between each digit. The child had to repeat back the digits in each string in correct order. The strings started with only two digits, and one digit was added for each new digit string. The test continued 
until the child made a mistake in two strings in a row. The child got two practice items with feedback support before the test items were presented. The performance score was the number of digits in the longest string repeated back correctly. The letter-span test was similar to the digit-naming test, but instead of digits, strings of consonant letters were used as stimuli. Again, two practice items with feedback support were provided before presenting the test strings. The performance score was the number of letters in the longest string repeated back correctly. In the further statistical analyses the two the scores were transformed into a composite score for short-term memory.

Reading ability was assessed by using two subtests: A word decoding test and a sentence reading test. In the word reading test, the task was to read 80 words aloud. The words varied in length (from 2 to 15 letters) and in phonological/orthographic complexity. The Latvian language is a far more consistent language than English, making it easier to recode words phonologically.

All words were written in lower-case letters on a sheet of paper and presented in 12-point font. Two practice items with feedback support were provided, but no feedback was given for the test items. The performance score was the number of words correctly read.

The child was presented with two practice sentences and 80 experimental sentences with five pictures below each sentence. The task was to read each sentence silently and choose one of the five alternative pictures corresponding to the target sentence. The children were given 10 minutes to perform the test, and the score was the total number of pictures correctly marked. The sentences varied in length, and the syntactical structure of the sentences was all in active form. In the present study, sentence reading was used as a measurement of reading comprehension. However, it has to be recognized that reading single sentences is a much simpler task than reading and interpreting paragraphs of texts. Sentence reading, therefore, only assesses elementary reading comprehension processes, and this limitation has to be taken into account when interpreting the results.

\section{Procedure}

All tests were administered to the children individually by trained research assistants. The tests were presented in the following order: phoneme segmentation, phoneme deletion, rapid object naming, color naming, short-term memory, word decoding, and sentence reading.

The test results were recorded on specially prepared scoring sheets, where the research assistants only were required to mark each child's response. Each assistant did the scoring 
individually in accordance with a clear description of how to score the different tests. In the kindergartens the tests were carried out during two weeks, and there were two test sessions for each child. In the schools, the children were assessed three times: In December and May in grade 1 , and in December in grade 2 . The tests were individually administered during a period of two weeks.

\section{RESULTS}

Descriptive data on the various tests are presented in Table 1. A mean raw score, standard deviation and range of scores are given for each assessment.

Table 1. Descriptive statistics for kindergarten, middle of the grade 1, end of grade 1, and the middle of grade $2(\mathrm{~N}=53)$

\begin{tabular}{|c|c|c|c|c|c|c|c|c|c|c|c|c|c|}
\hline \multirow[b]{2}{*}{ Task } & \multirow[b]{2}{*}{$\begin{array}{l}\text { Max. } \\
\text { Possible }\end{array}$} & \multicolumn{3}{|c|}{ Kindergarten } & \multicolumn{3}{|c|}{$\begin{array}{l}\text { Beginning of the first } \\
\text { grade }\end{array}$} & \multicolumn{3}{|c|}{ End of the first grade } & \multicolumn{3}{|c|}{ Second grade } \\
\hline & & Mean & SD & Range & Mean & SD & Range & Mean & SD & Range & Mean & SD & Range \\
\hline \multicolumn{14}{|c|}{ Phonemic awareness } \\
\hline $\begin{array}{l}\text { Phonemic } \\
\text { segmentation }\end{array}$ & 20 & 8.9 & 4.8 & $0-20$ & 12.8 & 4.8 & $1-20$ & 16.0 & 3.0 & $7-20$ & 15.9 & 2.5 & $10-20$ \\
\hline Phonemic deletion & 20 & 12.3 & 4.3 & $1-20$ & 16.0 & 3.9 & $2-20$ & 17.5 & 2.3 & $10-20$ & 17.8 & 1.7 & $13-20$ \\
\hline \multicolumn{14}{|l|}{ Rapid naming } \\
\hline Object naming test & 180 & 45.8 & 10.4 & $27-70$ & 54.2 & 10.8 & $32-79$ & 58.4 & 11.1 & $37-89$ & 62.6 & 11.1 & $37-96$ \\
\hline Color naming test & 180 & 48.1 & 11.5 & $20-75$ & 55.0 & 12.5 & $33-85$ & 59.6 & 11.5 & $41-86$ & 65.6 & 12.1 & $37-93$ \\
\hline \multicolumn{14}{|l|}{$\begin{array}{l}\text { Verbal short-term } \\
\text { memory }\end{array}$} \\
\hline Digit span test & 9 & 4.2 & 1.0 & $2-6$ & 4.1 & 1.0 & $2-6$ & 4.6 & 1.0 & $3-7$ & 4.8 & I.I & $3-7$ \\
\hline Letter span test & 9 & 3.7 & 0.9 & $2-7$ & 3.9 & 0.9 & $2-6$ & 4.0 & 0.9 & $2-6$ & 4.2 & 0.8 & $2-6$ \\
\hline \multicolumn{14}{|l|}{ Reading tasks } \\
\hline $\begin{array}{l}\text { Word reading } \\
\text { (accuracy) }\end{array}$ & 60 & 45.8 & 10.4 & $3-60$ & 53.1 & 8.5 & $3-60$ & 55.5 & 3.9 & $44-60$ & 55.5 & 3.8 & $40-60$ \\
\hline Sentence reading & 80 & 19.4 & 9.4 & $5-50$ & 31.7 & 12.2 & $4-57$ & 38.6 & 11.6 & $20-73$ & 47.7 & 12.1 & $25-78$ \\
\hline
\end{tabular}


Despite the fact a few children on the phoneme tests (segmentation and phoneme deletion) and the word reading test, had ceiling effect, the tests still provide sufficient information to discriminate among the children. The sentence reading test, however, discriminated well across the four assessments.

The inter-correlation matrix (Bonferroni-corrected) is presented in Table 2. The data were collected from the kindergarten assessments.

Table 2. The intercorrelations betweeen tasks at the kindergarten level (Bonferroni corrected)

1. Segmentation $\quad 1.000$

2. Deletion $0.423^{* * *} 1.000$

3. Color naming $\quad 0.195 \quad 0.383 * 1.000$

4. Object naming $\quad 0.162 \quad 0.363 \quad 0.849 * * \quad 1.000$

5. Digit span $\quad 0.431^{*} \quad 0.325 \quad 0.435 * * \quad 0.360^{*} \quad 1.000$

$\begin{array}{lllllll}\text { 6. Letter span } & 0.341 & 0.215 & 0.416^{* *} & 0.384^{*} & 0.667^{* * *} & 1.000\end{array}$

$\begin{array}{llllllll}\text { 7. Word reading } & 0.598^{* * *} & 0.515^{* * *} & 0.315 & 0.329 & 0.454^{* *} & 0.383^{*} & 1.000\end{array}$

\begin{tabular}{lllllllll}
\hline . Sentence reading & $0.167 n s$ & $0.231 \mathrm{~ns}$ & $0.208 \mathrm{~ns}$ & $0.132 \mathrm{~ns}$ & $0.188 \mathrm{~ns}$ & 0.218 & $0.224 \mathrm{~ns}$ & 1.000 \\
\hline
\end{tabular}

Note. ${ }^{* * *}=\mathrm{p}<.001 ;^{* *}=\mathrm{p}<.01,{ }^{*}=\mathrm{p}<.05$.

The correlations between tests within a conceptual category (e.g. digit span and letter span) are generally high and justify the composite scores used in the further analyses.

An analysis of variance was performed to study the growth in word reading performance from kindergarten to the middle of grade $2(\mathrm{~N}=53)$. The analysis showed a significant increase in word reading ability $[\mathrm{F}(3,52)=75.974, \mathrm{p}<.001]$, and a supplementary polynomial contrast analysis demonstrated that the profile of the developmental curve was both linear $(p$ $<.001)$ and quadratic $(\mathrm{p}<.001)$.

Moreover, the development in sentence reading performance showed a clear and significant increase $[\mathrm{F}(3,52)=76.706, \mathrm{p}<.001]$, with a linear slope $(\mathrm{p}<.001)$.

Predicting word and sentence reading ability: The traditional approach

In order to investigate the contribution of the phonological factors on word and sentence reading ability, multiple regression analyses were performed with word and sentence reading as dependent variables, and with a phonemic awareness, rapid naming, and short-term memory as independent variables. 
In the first regression analysis the factor scores on the phonological skills in kindergarten were used as predictors, while the performance scores in word reading at 3 different points of time (middle of grade 1, end of grade 1, and middle of grade 2) were used as dependent variables. The results are presented in Table 3.

Table 3. How phonological skills in kindergarten predict later word and sentence reading

\begin{tabular}{|c|c|c|c|c|}
\hline \multirow[b]{2}{*}{ Reading Variable } & \multirow[b]{2}{*}{ Predictor } & $\begin{array}{l}\text { Beginning of first } \\
\text { grade }\end{array}$ & End of first grade & $\begin{array}{l}\text { Second Grade } \\
\text { Samples }\end{array}$ \\
\hline & & Unique $\mathrm{R}^{2}$ & Unique $\mathrm{R}^{2}$ & Unique $\mathrm{R}^{2}$ \\
\hline \multirow[t]{3}{*}{ Word Reading Test } & Phonemic Factor & $.274^{* *}$ & $.093^{*}$ & $.006 \mathrm{~ns}$ \\
\hline & Naming Factor & $.002 \mathrm{~ns}$ & $.056 \mathrm{~ns}$ & $.001 \mathrm{~ns}$ \\
\hline & Memory Factor & $.003 n s$ & $.017 \mathrm{~ns}$ & $.022 n s$ \\
\hline Sentence Reading & Phonemic Factor & $.159 *$ & $.087 \mathrm{~ns}$ & $.133^{*}$ \\
\hline \multicolumn{5}{|l|}{ Test } \\
\hline & Naming Factor & $.008 \mathrm{~ns}$ & $.01 \operatorname{lns}$ & $.000 \mathrm{~ns}$ \\
\hline & Memory Factor & $.006 \mathrm{~ns}$ & $.000 \mathrm{~ns}$ & $.000 \mathrm{~ns}$ \\
\hline
\end{tabular}

Note. ${ }^{*}=\mathrm{p}<0.05,{ }^{* *}=\mathrm{p}<0.01, \mathrm{~ns}=$ non-significant

The analysis revealed that phonemic awareness was the only powerful and significant predictor, explaining $27.4 \%$ of unique variance in word reading in the middle of grade 1 $(\mathrm{p}<.01)$, and $9.3 \%$ of the variance at the end of the grade $1(\mathrm{p}<.05)$. The phonemic factor did not predict word reading in the middle of grade 2 . The other predictor variables (rapid naming and short-term memory) did not predict variance in word reading at any stage in the word reading development.

A follow-up regression analysis was performed to see if phonemic awareness could explain unique variance in word reading even when controlling for differences in word reading in kindergarten (the autoregressive effect). Not surprisingly, variance in early reading ability was the most powerful predictor, explaining $24.3 \%$ of the variance in word reading in the middle of grade $1(\mathrm{p}<.01)$. However, it is important to note that phonemic awareness still accounted for unique $4.9 \%$ of the variance in word reading $(\mathrm{p}<.05)$. At the end of grade 1 the autoregressive effect predicted significantly $18.3 \%$ of the variance in word reading at the end of grade $1(\mathrm{p}<.01)$, while phonemic awareness did not contributed to explain additional variance. 
The same statistical approach was used to assess how phonological skills may predict sentence reading (see Table 3).

The hierarchical regression analysis revealed that phonemic awareness accounted for $15.9 \%$ of the variance in sentence reading in the middle of grade $1(\mathrm{p}<.01)$, but the factor did not account for significant variance at the end of grade 1. Somewhat surprising was the finding that phonemic factor nevertheless accounted significantly for $13.3 \%$ of the variance in sentence reading in the middle of grade 2. Neither rapid naming nor short-term memory had any predictive power at any time of sentence reading assessment.

When sentence reading scores in kindergarten were forced into the regression analysis as the first predictor (the auto-regressive factor), this factor did not account for any variance in sentence reading in the middle of grade 1 . However, the phonemic awareness still explained $3.7 \%$ of the variance in sentence reading $(\mathrm{p}<.05)$, whereas naming and memory did not account for any significant variance in sentence reading.

Predicting word and sentence reading ability: Growth curve analysis

We also examined whether or not an assessment technique based on the progress across the whole time period of testing (growth potential) is a more illuminating procedure than the more traditional prediction technique.

Table 4. How phonological skills predict the regression slopes of word and sentence reading.

\begin{tabular}{lll} 
Slope & Predictor & Unique $\mathrm{R}^{2}$ \\
\hline Slope of Word Reading & Phonemic Factor & $.152^{* * *}$ \\
& Naming Factor & $.046 \mathrm{~ns}$ \\
& Memory Factor & $.088 \mathrm{~ns}$ \\
\hline Slope of $\quad$ Sentence & Phonemic Factor & $.007 \mathrm{~ns}$ \\
Reading & & \\
& Naming Factor & $.010 \mathrm{~ns}$ \\
& Memory Factor & $.002 \mathrm{~ns}$ \\
\hline
\end{tabular}

Note. $^{* * *}=\mathrm{p}<0.001, \mathrm{~ns}=$ non-significant 
The b-values (the slope coefficients) for each child were calculated. Then regression analyses were performed using phonemic awareness, rapid naming, and short-term memory scores in kindergarten as predictor variables, with the b-values as dependent variables. The results are displayed in Table 4.

In the first analysis, the b-values for word reading growth were entered as dependent variable. The analysis showed that the phonemic factor predicted significantly $25.2 \%$ of the variance in the slope $(p<.05)$, whereas memory and naming did not explain any significant any variance in the slope.

In a follow-up analysis, the a-values were forced into the regression analysis as the first factor. This analysis showed that the auto-regressive factor accounted for $25.2 \%$ of the variance in the b-slope $(p<.001)$, while phonemic awareness explained an additional $7.8 \%$ of the variance $(\mathrm{p}<.05)$.

When the b-values for sentence reading growth were used as dependent variable, the results on the regression analysis revealed that the none of the predictor factors contributed significantly to explain variance in b-values. Even the sentence reading scores in kindergarten (the auto-regressive effect) did not significantly predict any variance in the b-slope for sentence reading.

\section{DISCUSSION}

In the present study, children were followed from kindergarten to the middle of grade 2 with regular assessments. Two different procedures were applied to examine the predictive power of the preschool assessment of phonological skills. The first method determined how these skills (phonemic awareness, rapid naming and verbal short-term memory) predicted word and sentence reading scores at different times - in the middle and at the end of the grade 1 and in the middle of grade 2. The second approach analysed individual growth curves on word reading and sentence reading from kindergarten till the middle of grade 2, i.e. the progress across the whole period of the testing. The same explanatory variables were employed in both approaches.

Phonemic awareness in kindergarten explained above one fourth of the variance in word reading half a year later, and about $9 \%$ of the variance at the end grade 1 . Even when controlling for the auto-regressive effect, phonemic awareness accounted for unique variance at the middle of grade 1 and again at the end of grade 1 . Our findings thereby provide further 
evidence on the importance of phonemic awareness for acquiring efficient reading ability (for a review, see Stanovich, 2000).

The predictive power of phonemic awareness as assessed in kindergarten decreased as a function of the time. By the middle of grade 2, phonemic awareness did not predict any variance in word reading. Obviously many factors determine the children's progress in reading, and phonemic awareness is only one of them. Children enter school and are given systematic instruction in reading, and this probably helps their phonemic awareness, too. Therefore, the decrease in predictive power over time does not mean that the relationship between phonemic awareness and reading ability at any one given point in time is necessarily less important than we have come to see in recent years.

The importance of the phonemic awareness factor for reading acquisition was also confirmed when using sentence reading as dependent variable. It is important to note that phonemic awareness explained unique variance in both measurements in grade 1 and in the middle of grade 2. Clearly phonemic awareness is also important for reading comprehension. However, we have to consider that the sentence test used in the present study was very simple, and that the results might have been different if more complex texts were used.

The lack of predictive power of short-term memory and rapid naming was somewhat surprising in light of earlier research findings (Bowers, 1995; Scarborough, 1998; Wagner et al., 1994; Wolf, 2001). However, the auto-regressive effect and the phonemic awareness factor might have accounted for most of the available variance to be explained.

When employing growth curve analysis, phonemic awareness was the only phonological factor which significantly accounted for variance in the reading slope, The main result found when using growth curve analysis is that phonemic awareness in general has a significant impact on early word reading, a finding that adds further evidence to the critical role of phonemic awareness as an initial enabling skill in early reading acquisition.

As reported the phonemic factor did not explain any significant variance in the b- slope for sentence reading. This unexpected result may be caused by unreliability connected with the sentence reading scores in kindergarten. As shown in Table 1, the mean value for sentence reading is not higher than the value expected from pure guessing (choosing one among 4 alternatives). Therefore, the result should be interpreted with caution. A major theoretical as well as practical issue is to explain why some children show a fast development in reading acquisition whereas other children make slow progress. The answering of this question certainly implies an important educational potential. 
In conclusion, the traditional prediction method determining the correlation between variables at the different points in time and the growth curve analysis are complementary strategies that provide a more complete picture of the predictive power of initial enabling skills. Whichever strategy is used, our results clearly indicate that phonemic awareness is the single most powerful predictor of early reading in a written language with a regular orthography such as Latvian.

\section{REFERENCES}

Adams, M. J. \& Bruck, M. (1995). Resolving the "great debate". American Educator, 19, 720.

Baddeley, A. (1986). Working memory. New York: Oxford University Press.

Badian, N. A. (1994). Do dyslexic and other poor readers differ in reading-related cognitive skills? Reading and Writing: An Interdisciplinary Journal, 6, 45-63.

Badian, N. A. (1995). Predicting reading ability over the long term: The changing roles of letter naming, phonological awareness and orthographic processing. Annals of Dyslexia, 45, 79-96.

Badian, N.A. (ed.) (2000). Prediction and prevention of reading failure. Baltimore, Maryland: York press.

Blachman, B. A. (1984). Relationship of rapid naming ability and language analysis skills to kindergarten and first-grade reading achievement. Journal of educational Psychology, 76, 610-622.

Blachman, B. A. (1994). What we have learned from longitudinal studies of phonological processing and reading, and some unanswered questions: A response to Torgesen, Wagner, and Rashotte. Journal of Learning Disabilities, 27, 287-291.

Bowers, P. (1995). Tracing symbol naming speed's unique contributions to reading disabilities over time. Reading and Writing: An Interdisciplinary Journal, 7, 1-28.

Bowers, P. \& Wolf, M. (1993). Theoretical links among naming speed, precise timing mechanisms and orthographic skill in dyslexia. Reading and Writing: An Interdisciplinary Journal, 5, 69-85.

Catts, H. (1993). The relationship between speech-language impairments and reading disabilities. Journal of Speech and Hearing Research, 36(9), 48-58. 
Hecht, S. A., Burgess S. R., Torgesen, J. K., Wagner, R. K., \& Rashotte, C. A. (2000). Explaining social class differences in growth of reading skills from beginning kindergarten through fourth-grade: The role of phonological awareness, rate of access, and print knowledge. Reading and Writing: An Interdisciplinary Journal, 12, 99-127.

Lundberg, I. \& Frost, J., \& Petersen, O. (1988). Effects of an extensive program for stimulating phonological awareness in preschool children. Reading Research Quarterly, 23, 263-284.

Lundberg, I., Olofsson, A. \& Wall, S. (1980). Reading and spelling skills in the first school year predicted from phonemic awareness skills in kindergarten. Scandinavian Journal of Psychology, 21, 159-173.

O'Connor, R. \& Jenkins, J. (1999). Prediction of reading disabilities in kindergarten and first grade. Scientific Studies of Reading, 3, 159-197.

Olson, R. \& Wise, F., Johnson, M., \& Ring, J. (1997). The etiology and remediation of phonological based word recognition and spelling disabilities: Are phonological deficits the "hole story"? In B. Blachman (Ed.), Foundations of reading acquisition and dyslexia. Implications for early intervention. London: Lawrence Erlbaum Associates.

Santa, C. \& Høien, T. (1999). An assessment of Early Steps: A program for early intervention of reading problems. Reading Research Quarterly, 34, 54-79.

Scanlon, D. M. \& Vellutino, F. R. (1997). Instructional influences on early reading success. Perspectives. The International Dyslexia Association, 23, 35-37.

Scarborough, H. (1998). Early identification of children at risk for reading disabilities: Phonological awareness and some other promising predictors. Pp. 77-121 in B. K. Shapiro, P. J. Accordo, \& A. J. Capute (Eds.), Specific Reading Disability: A view of the Spectrum. Timonium, MD: York Press.

Snow, C. E., Burns, M. S., \& Griffin, P. (1998). Preventing reading difficulties in young children. Washington, DC: National Academy Press.

Stanovich, K. E. (2000). Progress in understanding reading. Scientific foundations and new frontiers. New York: The Guildford Press.

Stanovich, K. E., Cunningham, A. E., \& Cramer, B. (1984). Assessing phonological awareness in kindergarten children: Issues of task comparability. Journal of Experimental Child Psychology, 38, 175-190.

Torgesen, J. K., Wagner, R. K., \& Rashotte, C. A. (1997). Prevention and remediation of severe reading disabilities: Keeping the end in mind. Scientific Studies of Reading, 1, $217-$ 234. 
Torgesen, J. K., Wagner, R. K., Rashotte, C. A., Burgess, S., \& Hecht, S. (1997). Contributions of phonological awareness and rapid automatic naming ability to the growth of word-reading skills in second- to fifth-grade children. Scientific Studies of Reading, 1, 161-185.

Wagner, R. K. \& Torgesen, J. K. (1987). The nature of phonological processing and its causal role in the acquisition of reading skills. Psychological Bulletin, 101, 217-234.

Wagner, R. K., Torgesen, J. K., \& Rashotte, C. (1994). Development of reading-related phonological processing abilities: New evidence of bidirectional causality from a latent variable longitudinal study. Developmental Psychology, 30, 73-87.

Wolf, M. (Ed.) (2001). Dyslexia, fluency, and the brain. Timonium, Maryland: York Press.

\section{Acknowledgments}

This research was supported by grants from the Faculty of Psychology, University of Bergen, the Nordic Research Council and The Dyslexia Research Foundation, Stavanger, Norway. 


\title{
Report III
}

\section{Relations between enabling skills and reading comprehension: A follow-up study of Latvian students from first to second grade}

\author{
IEVA SPRUGEVICA \\ University of Latvia, Riga, Latvia
}

\section{TORLEIV HØIEN}

Dyslexia Research Foundation, Stavanger, Norway

\begin{abstract}
In order to examine the relationships among various phonological skills and reading comprehension, Latvian children were followed from grade 1 to grade 2 and were tested with a battery of phonological, word reading, and reading comprehension tasks. A principal component analysis of the phonological tasks revealed three salient factors: a phonemic awareness factor, a rapid naming factor, and a short-term memory factor. In order to analyze the relationship between various phonological skills and reading comprehension, a structural modeling analysis was performed. Phonemic awareness and rapid naming explained approximately the same amount of unique variance in reading comprehension, but phonemic awareness had most predictive power indirectly via word decoding. Only rapid naming had a significant direct impact on reading comprehension.
\end{abstract}

Key words: Phonological skills, phonemic awareness, verbal short-term memory, rapid naming, reading comprehension.

Ieva Sprugevica, University of Latvia, Jurmalas g. 74/76, Riga, LV-1083, Latvia. E-mail: ievasp@latnet.lv. 
Several studies have documented the relationship between various phonological skills and reading acquisition (for overview, see Badian, 2000; Blachman, 1997; Høien \& Lundberg, 2000; Snow, Burns, \& Griffin, 1998; Snowling, 2000; Stanovich, 2000). Especially three skills have been at the focus of interest: phonemic awareness, rapid naming, and verbal-short term memory.

Phonemic awareness refers to the ability to segment a word into its constituent phonemes and the ability to consciously manipulate these linguistic units. Most studies have concluded that phonemic awareness is the single most important phonological factor underlying efficient reading acquisition (Brady 1997; Lundberg \& Høien, 2001; Share \& Stanovich, 1995; Wagner, Torgesen, Rashotte, Hecht, Barker, Burgess, Donahue, \& Garon 1997), and skill in phonemic awareness in preschool children can successfully predict later reading achievement (for overview, see Badian 2000; Lundberg, Frost, \& Petersen, 1988; Snow, Burns, \& Griffin, 1998). Finally, difficulties in phonemic awareness have also been identified as the most critical factor underlying the severe word-decoding problems displayed by reading-disabled individuals (for overview, see Adams, 1990; Blachman, 2000; Rack, Snowling, \& Olson, 1992; Snowling, 1981, 2000).

It is also well documented that automatic word decoding skill is a prerequisite for understanding written text (Perfetti, 1985; van der Leij \& van Daal, 1999). A slow and faulty word decoding process consumes cognitive resources, leaving less mental resources available for the comprehension process (for overview, see Høien \& Lundberg, 2000; Stothard \& Hulme, 1992).

We should also consider the possibility of there being a direct connection between phonemic awareness and reading comprehension. Phonemic awareness requires the student to have achieved a level of cognitive ability where it is possible to perform "decentering" (cf Piaget's theory). The student's ability to reflect on his/her reading process is thus probably related to more general metacognitive processes that facilitate text comprehension (Byrne, Fielding-Barnsley, Ashley, \& Larsen, 1997; Lundberg, 1978; Tunmer \& Chapman, 1995). In this way lack of phonemic awareness may more directly impede reading comprehension (Adams, 1990; Share \& Stanovich, 1995) over and above what is mediated by poor word decoding.

Rapid naming is another phonological skill that may have impact on reading comprehension. Rapid naming refers to the ability to retrieve words very quickly. It is usually 
assessed through the ability to name colors, letters, numbers or objects quickly upon their presentation. It is considered relevant to reading because it is indicative of how readily children can gain access to a sound, a speech sound-sequence, or a word meaning (Bowers \& Swanson, 1991; Cornwall, 1992) and efficiently process long, ordered strings of items. Thus, rapid naming is expected to have a direct influence on reading comprehension.

Performance in reading comprehension may also depend on verbal short-term memory. Verbal short-term memory refers to the temporary storage of information that is being processed in any of a range of cognitive tasks. When decoding words, the beginning reader has to be able to decode a series of graphemes, and temporarily store the resultant phonemes in the correct order. Because this blending process demands valuable cognitive resources, it is important that the storage of the sounds functions smoothly.

Scarborough (1998) refers to eleven studies that report moderate and significant correlations between short-term memory skills and reading ability. Short-term memory is also important when constructing meaning above the level of identifying single words (McDougal \& Hulme, 1994; Oakhill \& Yuill, 1996; Scanlon \& Vellutino, 1997; Stothard, 1994). For example, when reading sentences, the reader needs to have lexical access to the phonological and semantic identities of many words at the same time. The short-term memory also stores phonological identities at the word level, and this information is critical for obtaining success when reading and interpreting sentences.

Phonological skills may have both an indirect and a direct impact on reading comprehension. The indirect impact goes through word decoding, and, as already mentioned, it is clearly documented that word decoding and reading comprehension are highly correlated (for overview, see Adams, 1990; Jackson \& Coltheart, 2001; Snowling, 2000). Especially at the early stage of learning to read, ability in word decoding explains most of the variance in reading written text (Share, 1995; Share \& Stanovich, 1995). Due to the fact that abilities in phonological skills, and primarily ability in phonemic awareness, play a critical role in acquiring word decoding competence (see Stanovich, 2000), we may assume that phonological skills have a substantial indirect impact on reading comprehension. On the other hand, it is also possible that phonological skills may have a direct impact on reading comprehension above and beyond the indirect influence via word decoding.

In sum, the present study investigates both the interrelationships between phonemic awareness, rapid naming and verbal short-term memory among Latvian students in grade 1, 
and the power each of these phonological skills might have in predicting variance in reading comprehension ability one year later. In contrast to most earlier studies addressing the relationship between enabling skills and reading comprehension, the present study has a longitudinal design allowing a stronger interpretation of causal directions. The structural modeling approach taken in the present study will then have a stronger empirical foundation than has been the case in earlier cross-sectional studies.

\section{METHOD}

\section{Subjects}

A total of 55 monolingual Latvian-speaking first grade students ( 29 girls and 26 boys), were selected to participate in the follow-up study from grade 1 to 2 . Their age in grade 1 ranged from 7 to 8 years $(M=7$ years and 3 months, $S D=4.4$ months $)$. Four students moved away during first grade, and thereby, leaving 51 as participants in the follow-up study. The drop out of children seemed to be rather random, primarily caused by parents moving to other cities in Latvia.

The students belonged to seven different public schools in the city of Riga, where families in this community were predominantly of lower middle-class to middle-class income level.

\section{Tests}

The tests in the present study assessed both phonological skills and reading ability.

Two tests were used to assess phonemic awareness: phoneme deletion and phoneme segmentation.

Phoneme deletion: This test assessed the child's ability to identify and delete the first or the last phoneme of the target word and provide the pronunciation of the word or nonword remaining after this deletion. The target phonemes were consonants in 17 of the test items and vowels in 3 items. The test had two practice items with feedback support and 20 experimental items without feedback. The words varied in length from 3 to 10 phonemes (mostly onesyllable and two-syllables words), and all of them were selected from the vocabulary used by children at this age. Experienced school teachers constructed the word list based on their thorough knowledge of the typical vocabulary of children at this age. For the first half of the items, the children were asked to delete the initial phoneme; for the second half, they had to delete the final phoneme. In 7 test items the phoneme deletion produced a word, whereas in 
13 test items the correct answer was a pronounceable nonword. The performance score was the total number of correct responses.

Phoneme segmentation: The phoneme segmentation test assessed the child's ability to identify the constituent phonemes of orally presented words. The test included two practice items with feedback support, and 20 experimental items without feedback. The words varied from short and phonologically simple words at the beginning of the test to longer and phonologically complex words at the end (from 4 to 9 phonemes). All words were a part of the children's receptive vocabulary. The experimenter read the word aloud with normal speed and articulation. The children had to segment the word into its constituent phonemes and provide the sounds aloud. The performance score was the number of words segmented correctly.

Two subtests were used to assess rapid naming: object naming and color naming.

Object naming: This test was used to assess the child's ability to retrieve the phonological representation of words presented as drawings on a sheet of paper. Five familiar objects were depicted: an apple, a house, a tree, a sun, and a star. The drawings of each object occurred several times in random order on the sheet (total number of pictures on the sheet was 180). Time limit was 1 minute. A practice task was given showing all five drawings with feedback response. The performance score was the total number of objects named correctly during the testing time.

Color naming: This subtest was similar to object naming. The task consisted of 5 colors: black, green, blue, red, and yellow, which occurred several times in random order on a sheet of paper (total number of items on the sheet was 180). A practice task with feedback for all five colors was given. The performance score was the number of correctly named colors during a time limit of one minute.

Verbal-short term memory was assessed by a digit-span test and by a letter-span test.

Digit span: The Digit Span subtest of the Wechsler Intelligence Scale for Children Revised (WISC-R; Wechsler, 1974) was used to assess memory for digits. The strings of digits were presented orally with about $\mathrm{I} / 2$ second between each digit. The child had to repeat the digits in each string in correct order. The strings started with only two digits, and one digit was added for each new digit string. The test continued until the child made a mistake on two subsequent strings. The child got two practice examples with feedback support before the test items were presented, but otherwise no feedback was given. The performance score was the number of digits in the longest string repeated correctly. 
Letter span: This test was similar to the digit-naming test, but instead of digits, strings of letters were used. Again, two practice examples with feedback support were provided before presenting the letter strings. The performance score was the number of letters in the longest string repeated correctly.

Reading words: The task was to read a series of 60 experimental words aloud. The words varied in length (from 2 to 15 letters), number of syllables (from 1 to 8 syllables), and phonological/orthographic complexity. All words were written on a sheet of paper and presented in a 12-point font. Two practice tasks with feedback support were given, but no feedback was given on the experimental tasks. Again, two kinds of performance scores were registered: (1) the number of correctly read words, and (2) the time (in seconds) taken to read the words. A combined word reading score was calculated by dividing accuracy by time, and this measure was used in the subsequent analyses.

Reading nonwords: This task consisted of 60 experimental non-words and with two practice items with feedback support. The nonwords were constructed with the similar level of phonological complexity as commonly encountered in the Latvian language. The nonwords varied in length from 3 to 13 letters, and the number of syllables varied from 1 to 5 . All nonwords were presented on a sheet of paper, again with 12 point font. Two kinds of performance scores were registered: (1) the number of nonwords decoded correctly and (2) the time (in seconds) taken to decode the nonwords. A combined nonword reading score was calculated by dividing accuracy by time, and this measure was used in the subsequent analyses.

Reading comprehension was assessed by two tests: sentence reading and text reading. Sentence reading: The child was presented with two practice sentences and 60 experimental sentences with five pictures below each sentence. The task was to read each sentence and choose the one of the five alternative pictures that corresponded to the target sentence. Feedback support was given on the two practice sentences. During the experimental tasks, however, no feedback was provided. The time limit for this test was 10 minutes. The sentences used varied in length and syntactical structure, and they were all in active form. The performance score was the total number of pictures correctly marked during the time provided.

Text reading: The children were presented with three passages along with multiple choice questions for each. They were asked to read a text and choose the one of the four alternative answers that corresponded to the target question. Each passage was printed on a separate sheet of paper. The texts were presented in order of increasing difficulty from 7 to 10 sentences. 
There were 4 questions after the first text and 6 questions after the last two texts. Two kinds of performance scores were registered concerning each text: (1) the number of answers marked correctly and (2) the time (in seconds) taken to complete the text with answers. For each of the subtests, an index score for text reading efficiency was calculated by dividing accuracy by reading time, and finally a composite text score was calculated by adding the index scores on the three texts employed. This composite score was used as a measure of text reading ability.

\section{Procedure}

The first assessment was administered in the middle of grade 1 and repeated one year later. The tests were administered to the children individually by trained research assistants during one or two sessions. In order to provide optimal testing conditions, no session exceeded a time limit of 30 minutes.

The test results were recorded on specially prepared scoring sheets, where the research assistants were only required to mark each child's response. Each assistant did the scoring individually in accordance with a clear description of how to score the different tests. All scoring was checked by one of the researchers responsible for the study.

\section{RESULTS}

\section{Descriptive data}

Table 1 presents the means, standard deviations, maximum scores, ranges, and skewness for all variables used in the present study.

The scores on the various phonological tasks had approximately normal distribution. A modest ceiling effect was found for the subtests phoneme deletion and phoneme segmentation. The sentence reading test also showed a normal distribution, while minor skewness was found on word reading and text reading.

The correlation matrix presented in Table 2 shows the Pearson correlations (Bonferroni corrected) between the various tests used in the present study. 
Table 1. Means, standard deviations and ranges for the measures of phonological skills and reading abilities

Task Mean SD Max. Range Skewness

Phoneme deletion

Phoneme segmentation

Object naming

Color naming

Digit span

Letter span

Word reading:

Word reading (accuracy) $\quad 55.28$

Word reading (time in sec.) $\quad 128.02$

Nonword reading:

Nonword reading (accuracy)

Nonword reading (time in sec.)

Sentence reading

Text reading:

1. Text reading (accuracy)

1. Text reading (time in sec.)

101.71

2. Text reading (accuracy)

3.82

2. Text reading (time in sec.)

147.76

3. Text reading (accuracy)

4.80

3. Text reading (time in sec.) $\quad 279.10$
3.78

4.97

11.26

12.63

1.03

.96

4.14

60

20

$-1.80$

68.21

316

272

1.14

9.03

60

45

$-1.56$

76.80

478

390

1.47

12.36

78

53

.64

62.58

.48

85.07

1.27

155.26

$\begin{array}{rr}4 & 2 \\ 310 & 271 \\ 4 & 2 \\ 422 & 372 \\ 6 & 4\end{array}$

656
$-1.31$

2.12

$-2.80$

1.57

$-.91$

1.17

Note. Phonological skills were assessed in the middle of grade 1 , reading tasks - in the middle of grade 2.

Not unexpectedly, the highest correlations were found between the following subtests:

Phonemic segmentation and phonemic deletion, between color and object naming, and between digit-span and letter-span, respectively. Almost all phonological tasks (except the short-term memory tests) correlated significantly with reading tasks, and the reading tasks assessed in the study were significantly correlated with each other. 
Table 2. Correlation matrix of phonological skills and reading abilities (Bonferroni corrected)

$\begin{array}{llllllllll}\text { Tests } & 1 . & 2 . & 3 . & 4 . & 5 . & 6 . & 7 . & 8 . & 9 .\end{array}$

1. Phoneme $\quad 1.000$

deletion

2. Phoneme $\quad .676^{* *} \quad 1.000$

segmentation

$\begin{array}{llll}3 . & \text { Object } \quad .168 \quad .141 \quad 1.000\end{array}$

naming

$\begin{array}{lllll}\text { 4. Color } & .117 & .111 & .839^{* *} & 1.000\end{array}$

naming

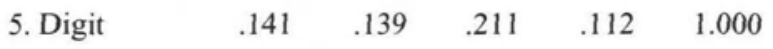

span

$\begin{array}{lllllll}6 . \text { Letter } & .102 & .075 & .065 & .007 & .447 * * & 1.000\end{array}$

span

$\begin{array}{llllllll}\text { 7. Word reading } & .569 * & .501 * & .331 * & .286^{*} & .107 & .122 & 1.000\end{array}$

(index)

$\begin{array}{llllllllll}8 . & \text { Nonword } & .599 * & .554^{*} & .233^{*} & .216^{*} & .121 & .129 & .569 * * & 1.000\end{array}$

reading (index)

$\begin{array}{lllllllllll}\text { 9. Sentence } & .245^{*} & .207 & .271^{*} & .205^{*} & .110 & .119 & .323^{*} & .301 * & 1.000\end{array}$

reading

10. Text reading $\quad .176 \quad \begin{array}{llllllllll}.141 & .208 & .221^{*} & .112 & .066 & .287^{*} & .219^{*} & .589 * * & 1.000\end{array}$ (index)

Note: Significance level of correlation (two tailed): ${ }^{*} \mathrm{p}<05,{ }^{* *} \mathrm{p}<01$.

\section{Interrelationships between phonological skills}

One way to conceptualize the relationships among the phonological skills is in terms of the factor composition. A principal component analysis (rotated, varimax) was run on 6 subtests. The analysis yielded 3 factors with eigenvalues greater than one. The results are displayed in Table 3. 
Table 3. Principal components loadings for all phonological variables

\begin{tabular}{lcll} 
Variables & Naming & Phonemic awa. & Memory \\
\hline Variance explained & $46.36 \%$ & $23.01 \%$ & $14.79 \%$ \\
\hline Phoneme segmentation & 0.205 & 0.894 & 0.081 \\
Phoneme deletion & 0.213 & 0.870 & -0.166 \\
Color naming & 0.919 & 0.252 & -0.020 \\
Object naming & 0.937 & 0.187 & 0.096 \\
Digit span & 0.249 & 0.231 & 0.785 \\
Letter span & -0.204 & 0.025 & 0.890
\end{tabular}

Note. Phonemic awa. $=$ phonemic awareness

The first factor loaded highly on two subtests: phoneme segmentation and phoneme deletion and was labeled phonemic awareness. A second factor, labeled rapid naming, loaded highly on object naming and color naming. The third factor, which was called short-term memory, loaded highly on the tasks assessing digit and letter span. Altogether the three factors explained $84.2 \%$ of the total variance. Most of the variance was explained by rapid naming (46.4\%), whereas phonemic awareness accounted for $23.0 \%$ of the variance. Finally shortterm memory only explained $14.8 \%$ of the total variance.

Our results provide additional evidence that phonological skills are not a unitary construct, but reflect separate underlying skills (McDougal \& Hulme, 1994).

\section{Relationship between phonological skills and reading comprehension}

One way to conceptualize direct and indirect relationships among the variables is in terms of structural modeling analyses. Figure 1 presents a structural model with the manifest and latent variables used in the present study. The suggested model is a formalization of the assumptions proposed in the introductory section. However, possible direct effects of the phonological subskills on reading comprehension have not been marked. 


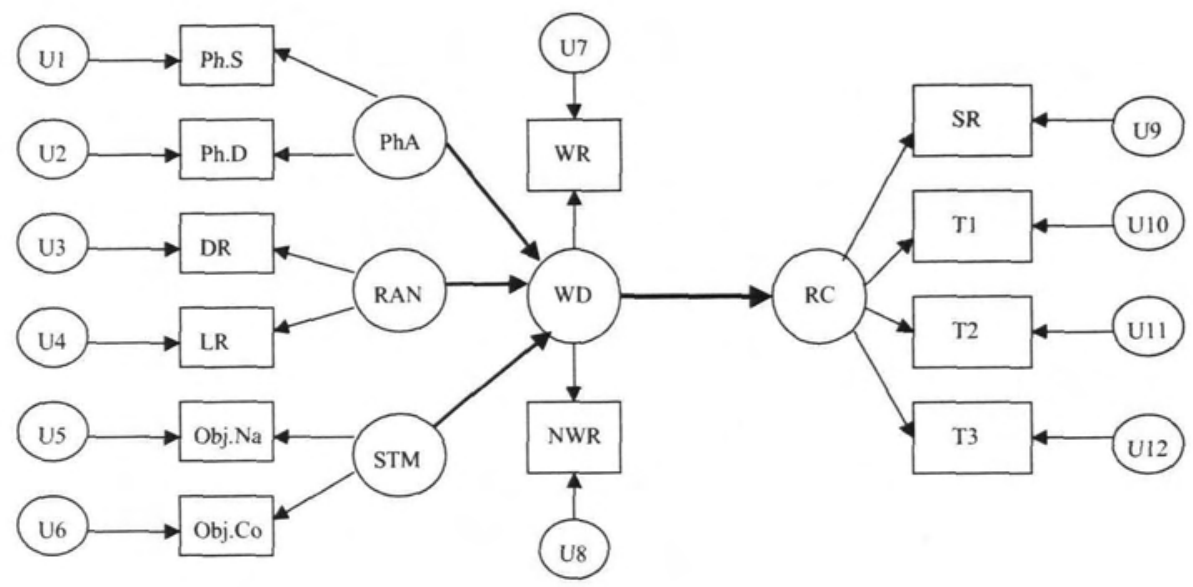

Figure 1. Latent and manifest variables in the structural model.

Note: $U=$ Unique variance, $\mathrm{Ph} . \mathrm{S}=$ Phonological Segmentation, $\mathrm{Ph} . \mathrm{D}=$ Phoneme Deletion, $\mathrm{DR}=$ Digit Repeating, $\mathrm{LR}=$ Letter Repeating, $\mathrm{Obj} . \mathrm{Na}=$ Object Naming, Obj. $\mathrm{Co}=$ Object colour, $\mathrm{PhA}=$ Phoneme Awareness, RAN $=$ Rapid naming, STM $=$ Short-term Memory, WD $=$ Word Decoding, $W R=$ Word recognition, NWR $=$ Nonword Decoding, $\mathrm{RC}=$ Reading Comprehension, $\mathrm{SR}=$ Sentence Reading, $\mathrm{Tl}$ : Text 1 , $\mathrm{T} 2=$ Text $2, \mathrm{~T} 3=$ Text 3 .

In structural analyses there are in particular two indices of importance when evaluating whether or not (or to what degree) the models meet the demands of fitness: The Steiger-Lind RMS index, and the Adjusted Population Gamma Index. The RMS index can be thought of as a root mean square standardized residual, adjusted for model complexity. Index value below .10 indicates that the model has an acceptable fitness. Adjusted Population Gamma Index is another measure of a model's suitability, and this index is described as "a coefficient of a model determination adjusted for model complexity". Values above .90 are considered to indicate good fitness, while values over .95 show, according to Steiger (1989), excellent fitness. In the present study, structural modeling was assessed by using the statistical program called EZPath (Steiger, 1989). The model presented in Figure I had a good fitness with a Steiger-Lind RMS index equal to .097 , and with an Adjusted Population Gamma Index of 92.

Figure 2 displays a simplified version of the structural model presented in Figure 1, depicting the latent variables for phonemic awareness, rapid naming, short-term memory, 
word decoding, and reading comprehension. The path coefficients are written on the arrows connecting the latent variables.

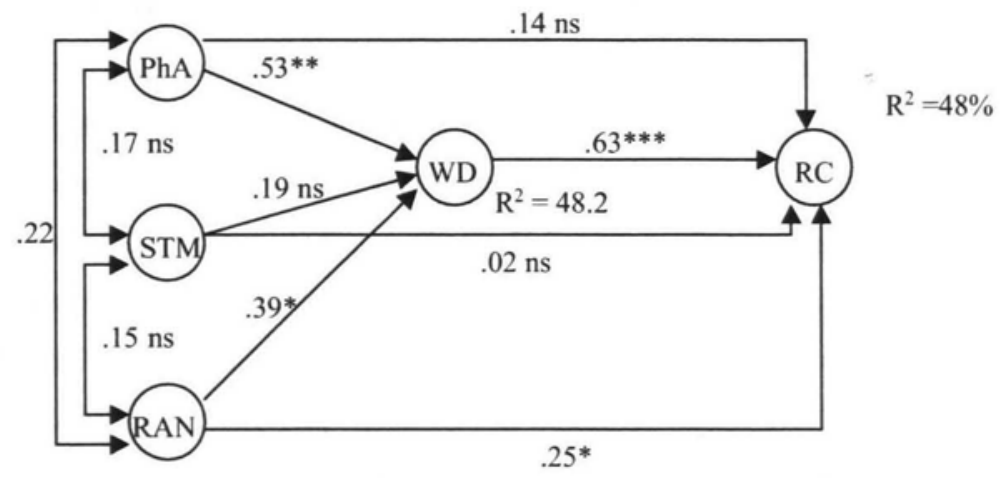

Figure 2. Path correlations between latent variables.

Note: $\mathrm{PhA}=$ Phonemic Awareness, $\mathrm{RAN}=$ Rapid Naming, $\mathrm{STM}=$

Short-term Memory, WD $=$ Word Decoding, $\mathrm{RC}=$ Reading

Comprehension. ${ }^{*}=\mathrm{p}<.05,{ }^{* *}=\mathrm{p}<.01,{ }^{* * *}=\mathrm{p}<.001$. 
In the present study, both phonemic awareness and rapid naming had a significant indirect impact (via word decoding) on later reading comprehension. Indirectly phonemic awareness accounted for about $11.6 \%$ of the variance in reading comprehension $(b=.33, p<.05)$ The $b$ coefficient is equal to the product of the coefficient between phonemic awareness and word decoding $(b=.53, \mathrm{p}<.01)$ and the coefficient between word decoding and reading comprehension $(\mathrm{b}=.63, \mathrm{p}<.001)$. As shown in Figure 2, the direct impact from phonemic awareness on reading comprehension was not significant.

The findings were not unexpected. Previous research has documented that phonemic awareness is critical in acquiring efficient word decoding ability, and skills in word decoding is a prerequisite for reading comprehension (Badian, 1993; Bowers \& Swanson, 1991; Vandervelden \& Siegel, 1995; Wagner, Torgesen, \& Rashotte, 1994). The predictive power of phonemic awareness to account for variance in reading performance is also reported by Sprugevica and Høien (in print, b) where both traditional hierarchical regression and linear growth curve analyses were used. In the present study, however, phonemic awareness did not have any direct impact on reading comprehension $(b=.14, p=n s$.).

Compared with phonemic awareness, rapid naming explained indirectly only $6.3 \%$ of the variance in the dependent variable $(\mathrm{b}=.25, \mathrm{p}<.05)$. The low indirect relationship between rapid naming and reading comprehension is also in accordance with earlier research reporting correlation coefficients between .30 and .40 between these two variables (Bowers \& Swanson, 1991; Wagner et al., 1994). However, it is interesting to notify that rapid naming had a significant direct impact on reading comprehension explaining $6 \%$ of unique variance in the independent variable $(\mathrm{b}=.25, \mathrm{p}<.05)$.

It was somewhat surprising that short-term memory did not have any significant impact on reading comprehensions, neither directly nor indirectly. Earlier research has reported significant correlation between short-term memory and word decoding varying between .28 and .44 (Bowers \& Swanson, 1991; Bowey, Cain, \& Ryan, 1992; Wagner et al., 1994). As expected, the path coefficient between word decoding and text reading was high $(b=.63, p<$ $.001)$.

\section{DISCUSSION}

Our study shows that both phonemic awareness and rapid serial naming had significant indirect impact on reading comprehension, but phonemic awareness was most powerful. On the other hand, only rapid naming had a direct impact on reading comprehension. 
There has been some discussion about the relationship between phonemic awareness and rapid naming. Wagner and Torgesen (1987) assumed them both to be a reflection of a unitary phonological process. Other researchers, however, did not find any strong correlation between these two skills (Badian, 1993; Cornwall, 1992; Felton \& Brown, 1990). This suggests that rapid-naming tasks appear to measure something separate from phoneme awareness (for overview, see Wolf, 2001). Students who have problems with both tasks tend to be at the lowest end of the reading continuum, indicating that a "double-deficit" may cause these severe reading difficulties (Wolf \& Bowers, 1999). In a study by Sprugevica and Høien (in print, a), among the same students one year earlier when they attended kindergarten, the analysis gave three different latent factors: Phonemic awareness, rapid-naming, and shortterm memory. Obviously early reading teaching does not cause any difference regarding the issue.

In our analyses phonemic awareness contributed to explain indirectly a substantial amount of variance in reading comprehension. This finding is in accordance with an abundance of earlier research showing that phonemic awareness is as strong predictor for future reading (Blachman, 1997; Bradley \& Bryant, 1983; Lundberg et al., 1988; Lundberg \& Høien, 1989; McGuinness, 1997; Share, 1995; Snowling \& Nation, 1997).

However, phonemic awareness did not have any direct impact on reading comprehension. Our results, thereby, are not in accordance with findings by Engen and Høien (in print) who reported that phonemic awareness directly explained $15 \%$ of the variance in reading comprehension.

In our study rapid serial naming had both indirect and direct impact on variance in reading comprehension. The indirect impact was substantially lower than the impact from phonemic awareness (only about half the size). But nevertheless, rapid naming is correlated with word decoding, and thereby indirectly related to reading comprehension. An interesting finding in the present study is that rapid naming directly explained about $6 \%$ of the variance in reading comprehension. When summarising the direct and indirect impact on reading comprehension, our findings show that phonemic awareness and rapid naming contributed to explain approximately the same amount of unique variance in the dependent variable. Thereby our findings are in accordance with Scarborough (1998) who in her review of longitudinal studies concluded that rapid naming is at least as strongly related to later reading skills as phonemic awareness. Other researchers, for example, Pennington, Cardoso-Martins, Green, \& Lefly (2001) claim that rapid serial naming is less powerful at explaining variance in reading skills 
than phonemic awareness. However, they also report that variation in rapid serial naming is particularly important for fluent text reading, whereas phonemic awareness is important for development of the ability to read. Therefore, it seems reasonable to assume that naming is more related to reading at later stages in reading development, for example when the reader is using an orthographic decoding strategy and has to name the words quickly (see also Wolf, 2001).

This assumption is also in accordance with findings reported by Sprugevica and Høien (in print, b). When using a similar test battery, phonemic awareness was the only factor among students in kindergarten that significantly contributed to explain variance in sentence reading. Obviously the age when the assessments are performed, is a critical factor. Among students in kindergarten, who are about to acquire competence in understanding and using the alphabetic principle, phonemic awareness is clearly a more powerful predictor of reading achievement. However, later on, as for example in grade 2, phonemic awareness for most of the children presumably has been sufficiently acquired via having learned the alphabetical principle, reading may be more dependent on rapid naming.

In the present study, no significant direct or indirect path coefficients were found between verbal-short term memory and reading comprehension. This result was somewhat surprisingly. Studies assessing correlations between verbal short-term memory and word decoding have found correlations between 0.25 and 0.45 (Bowers \& Swanson, 1991; Bowey et al., 1992; Wagner et al., 1994). However, there are some studies which show that shortterm memory is not significantly related to reading when phonemic awareness is partialed out (Rohl \& Pratt, 1995; Wagner et al., 1994). In the present study reading comprehension, not word decoding, was the dependent variable. When addressing reading comprehension, presumably more complex memory processes are needed than those needed when decoding single words. The work of numerous investigators has shown that the relationship between memory skills and reading comprehension is not straightforward (Stothard, 1996). For example, a student reading a sentence in a text must have access to previously mentioned actors and objects in order to grasp who or what the pronouns are referring to. $\mathrm{He} / \mathrm{she}$ also needs contextual information to integrate coherently information presented in the current sentence with the text previously read. Therefore, a reader may be unable to comprehend a written sentence even when he/she has lexical access to each single word in the sentence (Stothard \& Hulme, 1992; Yuill \& Oakhill, 1991). The simple short-term memory tasks used in the present study are probably not powerful enough to capture the more critical working memory processes most important when reading connected text. 
Our results should be interpreted with some caution. The sample in the present study is somewhat restricted. A more comprehensive study is recommended. When including more students it will be possible to run separate analyses for subgroups of students, for example students with dyslexia. It may be the case that the predicative power of different phonological skills on reading comprehension may vary depending on the skills in word decoding.

\section{REFERENCES}

Adams, M. (1990). Beginning to read: Thinking and learning about print. Cambridge, MA: MIT Press.

Badian, N.A. (1993). Phonemic awareness, naming, visual symbol processing, and reading. Reading and Writing: An Interdisciplinary Journal 5: 87-100.

Badian, N.A. (Ed.) (2000). Prediction and prevention of reading failure. Baltimore, Maryland: York Press, Inc.

Blachman, B.A. (Ed.) (1997). Foundations of reading acquisition and dyslexia, implications for early intervention. Mahwah, NJ: Erlbaum.

Blachman, B.A. (2000). Phonological awareness. In M.L. Kamil, P.B. Mosenthal, P.D. Pearson \& R. Barr (Eds.), Handbook of Reading Research. Volume III (pp. 483-502). Mahwah, NJ: Erlbaum.

Bowers, P.G. \& Swanson, L.B. (1991). Naming speed deficits in reading disability: Multiple measures of a singular process. Journal of Experimental Child Psychology 51: 195-219.

Bowey, J.A., Cain, M.T., \& Ryan, S.M. (1992). A reading-level design study of phonological skills underlying fourth grade children's word reading difficulties. Child Development 63: 999-1011.

Bradley, L. \& Bryant, P. (1983). Categorizing sounds and learning to read: A causal connection. Nature 303: 419-421.

Brady, S.A. (1997). Ability to encode phonological representations: An underlying difficulty of poor readers. In B.A. Blachman (Ed.), Foundations of reading acquisition and dyslexia. Implications for early intervention (pp. 21-47). Mahwah, NJ: Erlbaum.

Byrne, B., Fielding-Barnsley, R., Ashley, L., \& Larsen, K. (1997). Assessing the child's and the environment's contribution to reading acquisition: What we know and what we don't know. In B.A. Blachman (Ed.), Foundations of reading acquisition and dyslexia. Implications for early intervention (pp. 265-285). Mahwah, NJ: Erlbaum. 
Cornwall, A. (1992). The relationship of phonological awareness, rapid naming, and verbal memory to severe reading and spelling disability. Journal of Learning Disabilities 25: 532-538.

Engen, L. \& Høien, T. (in print). Phonological skills and reading comprehension. Reading and Writing: An Interdisciplinary Journal.

Felton, R.H. \& Brown, I.S. (1990). Phonological processes as predictors of specific reading skills in children at risk for reading failure. Reading and Writing: An Interdisciplinary Journal 2: 39-59.

Høien, T. \& Lundber. (2000). Dyslexia: From theory to intervention. Dordrecht: Kluwer Academic Publishers.

Jackson, N.E. \& Coltheart, M. (2001). Routes to reading success and failure. Ann Arbor, MI: Sheridan Books.

Lundberg, I. (1978). Aspects of linguistic awareness related to reading. In A. Sinclair, R.J. Jarvella \& W.J.M. Levelt (Eds.), The child's conception of language (pp. 83-96). Berlin: Springer Verlag.

Lundberg, I. \& Høien, T. (1989). Phonemic deficits - a core symptom of developmental dyslexia? The Irish Journal of Psychology 10: 579-592.

Lundberg, I. \& Høien, T. (2001). Dyslexia and phonology. In A. Fawcett (Ed.), Dyslexia: Theory and good practice (pp. 109-123). London: Whurr.

Lundberg, I., Frost, J., \& Petersen, O. (1988). Long term effects of a preschool training program in phonological awareness. Reading Research Quarterly 28: 263-284.

McDougal, S. \& Hulme, C. (1994). Short-term memory speech rate and phonological awareness as predictors of learning to read. In C. Hulme \& M. Snowling (Eds.), Reading development and dyslexia . London: Whurr.

McGuinness, D. (1997). Why our children can't read: And what we can do about it. New York: The Free Press.

Oakhill, J. \& Yuill, N. (1996). Higher order factors in comprehension disability: In C. Cornoldi \& J. Oakhill (Eds.), Reading comprehension difficulties. Processes and intervention (pp. 69-92). Mahwah, NJ: Erlbaum

Pennington, B., Cardoso-Martins, C., Green, P., \& Lefly, D. (2001). Comparing the phonological and double deficit hypotheses for developmental dyslexia. Reading and Writing: An Interdisciplinary Journal 14: 707-755.

Perfetti, C. (1985). Reading ability. New York: Oxford University Press. 
Rack, J., Snowling, M., \& Olson, R. (1992). The nonword reading deficit in developmental dyslexia: A review. Reading Research Quarterly 27: 28-53.

Rohl, M. \& Pratt, C. (1995). Phonological awareness, verbal working memory and acquisition of literacy. Reading and Writing: An Interdisciplinary Journal 7: 327-360.

Scanlon, D. \& Vellutino, F. (1997). Instructional influences on early reading success. Perspectives (The International Dyslexia Association) 23: 35-37.

Scarborough, H. (1998). Early identification of children at risk for reading disabilities: Phonological awareness and some other promising predictors. In B.K. Shapiro, P.J. Accardo \& A.J. Capute (Eds.), Specific Reading Disability: A View of the Spectrum (pp. 77-121). Timonium: MD: York Press.

Share, D. (1995). Phonological recoding and self-teaching: Sine qua non of reading acquisition. Cognition 55: 151-218.

Share, D. \& Stanovich, K. (1995). Cognitive processes in early reading development. Issues of Education: Contributions from Educational Psychology 1: 1-57.

Snow, C.D., Burns, M.S., \& Griffin, P. (Eds.) (1998). Preventing reading difficulties in young children. Washington DC: National Academy Press.

Snowling, M. (1981). Phonemic deficits in developmental dyslexia. Psychological Research 43: $219-234$.

Snowling, M. (2000). Dyslexia. Oxford: Blackwell.

Snowling, M. \& Nation, K. (1997). Language, phonology and learning to read. In C. Hulme \& M. Snowling (Eds.), Dyslexia: Biology, cognition and intervention (pp. 167-181). London: Whurr.

Sprugevica, I. \& Høien, T. (in print, a). Enabling skills in early reading acquisition: A study of children in Latvian kindergartens. Reading and Writing: An Interdisciplinary Journal.

Sprugevica, I. \& Høien, T. (in print, b). Early phonological skills and how they predict reading acquisition: A follow-up study from kindergarten to the middle of grade 2 . Scandinavian Journal of Psychology.

Stanovich, K. (2000). Progress in understanding reading. Scientific foundations and new frontiers. New York: The Guildford Press.

Steiger, J.H. (1989). EzPath, Causal modeling. A supplementary module for SYSTAT and SYGRAPH. Evanston, Illinois: Systat, Incorporation.

Stothard, S.E. (1994). The nature and treatment of reading comprehension difficulties in children. In C. Hulme \& M. Snowling (Eds.), Reading development and dyslexia (pp. 200238). London: Whurr. 
Stothard, S.E. (1996). Assessing reading comprehension. In M. Snowling \& J. Stackhouse (Eds.), Dyslexia: A practitioner's handbook (pp. 108-128). London: Whurr.

Stothard, S.E. \& Hulme, C. (1992). Reading comprehension difficulties in children. Reading and Writing: An Interdisciplinary Journal 4: 245-256.

Tunmer, W.E. \& Chapman, J.W. (1995). Context use in early reading development: Premature exclusion of a source of individual differences? Issues in education, 1, 97-100. van der Leij, A. \& van Daal, V. (1999). Automaticity, automatization and dyslexia. In I. Lundberg, F. Tønnessen \& I. Austad (Eds.), Dyslexia: Advances in theory and practice (pp. 75-89). Dordrecht: Kluwer Academic Publishers.

Vandervelden, M. \& Siegel, L. (1995). Phonological recoding and phoneme awareness in early literacy: A developmental approach. Reading Research Quarterly 30: 854-876.

Wagner, R. \& Torgesen, J. (1987). The nature of phonological processing and its causal role in the acquisition of reading skills. Psychological Bulletin 101: 192-212.

Wagner, R., Torgesen, J., \& Rashotte, C. (1994). The development of reading-related phonological processing abilities: New evidence of bi-directional causality from a latent variable longitudinal study. Development Psychology 30: 73-87.

Wagner, R., Torgesen, J., Rashotte, C., Hecht, S., Barker, T., Burgess, S., Donahue, J., \& Garon, T. (1997). Changing relations between phonological processing abilities and wordlevel reading as children develop from beginning to skilled readers: A 5-year longitudinal study. Developmental Psychology 33: 468-479.

Wechsler, D. (1974). Wechsler intelligence scale for children - revised. San Antonio, San Antonio, TX: Psychological Corp.

Wolf, M. (Ed.) (2001). Dyslexia, fluency, and the brain. Timonium, Maryland: York Press.

Wolf, M. \& Bowers, P.G. (1999). The double-deficit hypothesis for the developmental dyslexia. Journal of Educational Psychology 91: 415-438.

Yuill, N. \& Oakhill, J. (1991). Children's problems in text comprehension. Cambridge: Cambridge University Press.

\section{ACKNOWLEDGMENTS}

This research was supported by grants from the Faculty of Psychology, University of Bergen, the Nordic Research Council and The Dyslexia Research Foundation, Stavanger, Norway. A special thanks to Michael Evans and Mia Harbo for text preparation. 
Address for correspondence:

Ieva Sprugevica, University of Latvia,

Riga, LV - 1083, Latvia.

Phone: 3712417623 Fax: 3712417623 E-mail: ievasp@latnet.lv 


\section{Doctoral thesis at the Faculty of Psychology, University of Bergen}

1979-1980 Allen, H.M., Dr.philos. Parent-offspring interactions in willow grouse (Lagopus L. Lagopus).

1981-1982 Myhrer, T., Dr.philos. Behavioral Studies after selective disruption of hippocampal inputs in albino rats.

1982-1983 Svebak, S., Dr.philos. The significance of motivation for task-induced tonic physiological changes.

Myhre, G., Dr.philos. The Biopsychology of behavior in captive Willow ptarmigan.

Eide, R., Dr.philos.

PSYCHOSOCIAL FACTORS AND INDICES OF HEALTH RISKS. The relationship of psychosocial conditions to subjective complaints, arterial blood pressure, serum cholesterol, serum triglycerides and urinary catecholamines in middle aged populations in Western Norway.

Værnes, R.J., Dr.philos. Neuropsychological Effects of Diving.

1983-1984 Kolstad, A., Dr.philos. Til diskusjonen om sammenhengen mellom sosiale forhold og psykiske strukturer. En epidemiologisk undersøkelse blant barn og unge.

1984-1985 Løberg, T., Dr.philos. Neuropsychological assessment in alcohol dependence.

1985-1986 Hellesnes, T., Dr.philos. Læring og problemløsning. En studie av den perseptuelle analysens betydning for verbal læring.

Håland, W., Dr.philos. Psykoterapi: relasjon, utviklingsprosess og effekt.

Hagtvet, K.A., Dr.philos. The construct of Test Anxiety: Conceptual and methodological Issues.

1986-1987 Jellestad, F.K., Dr.philos. Effects of neuron specific amygdala lesions on fearmotivated behavior in rats.

Aarø, L.E., Dr.philos. Health Behaviour and Sosioeconomic Status. A Survey among the adult population in Norway.

Underlid, K., Dr.philos. Arbeidsløyse i psykososialt perspektiv.

Laberg, J.C., Dr.philos. Expectancy and classical conditioning in alcoholics' craving. 
1987-1988 Vollmer, F.C., Dr.philos. Essays on explanation in psychology.

Ellertsen, B., Dr.philos. Migraine and tension Headache: Psychophysiology, Personality and Therapy.

Kaufmann, A., Dr.philos. Antisosial atferd hos ungdom. En studie av psykologiske determinanter.

Mykletun, R.J., Dr.philos. Teacher Stress.

1988-1989 Havik, O.E., Dr.philos. After the myocardial infarction: A medical and psychological study with special emphasis on perceived illness.

1989-1990 Bråten, S., Dr.philos. Menneskedyaden. En teoretisk tese om sinnets dialogiske natur med informasjons - og utviklingspsykologiske implikasjoner sammenholdt med utvalgte spebarnsstudier.

Wold, B., Dr.philos. Lifestyles and physical activity. A theoretical and empirical analysis of socialization among children and adolescents.

1990-1991 Flaten, M.A., Dr.philos. The role of habituation and learning in reflex modification.

Alsaker, F.D., Dr.philos. Global negative self-evaluation in early adolescence.

Kraft, P., Dr.philos. $\quad$ AIDS prevention in Norway. Empirical studies on diffusion of knowledge, public opinion, and sexual behaviour.

1991-1992 Endresen, I.M., Dr.philos. Psychoimmuniological stress markers in working life.

Faleide, A.O., Dr.philos. Asthma and Allergy in Childhood. Psychosocial and Psychotherapeutic Problems.

Dalen, K., Dr.philos. Hemispheric Asymmetry and the Dual-Task Paradigm: An Experimental Approach.

Bø, I.B., Dr.philos. Ungdoms sosiale økologi. En undersøkelse av 14-16 åringers sosiale nettverk.

Nivison, M.E., Dr.philos. The Relationship between Noise as an Experimental and Environmental Stressor, Physiological Changes and Psychological Factors.

1992-1993 Torgesen, A.M., Dr.philos. Genetic and environmental influence on temperamental behaviour. A longitudinal study of 
twins from infancy to adolescence.

Larsen, S., Dr.philos. Cultural background and problem drinking.

Nordhus, I.H., Dr.philos. Family caregiving. A community psychological study with special emphasis on clinical interventions.

1993-1994 Thuen, F., Dr.philos.

Accident-related behaviour among children and young adolescents: Prediction and prevention.

Solheim, R., Dr.philos. Spesifikke lærevansker. Diskrepanskriteriet anvendt i seleksjonsmetodikk.

Johnsen, B.H., Dr.psychol. Brain assymetry and facial emotional expressions: Conditioning experiments.

Tønnessen, F.E.,

The etiology of Dyslexia.

Dr.philos.

Kvale, G., Dr.psychol. Psychological factors in anticipatory nausea and vomiting in cancer chemotherapy.

Asbjørnsen, A.E.,

Dr.psychol.

Structural and dynamic factors in dichotic listening:

An interactional model.

1994-1995 Bru, E., Dr.philos.

The role of psychological; factors in neck, shoulder and low back pain among female hospitale staff.

Braathen, E.T.,

Prediction of excellence and discontinuation in

Dr.psychol.

different types of sport: The significance of motivation and EMG.

Johannessen, B.F., Dr.philos.

Det flytende kjønnet. Om lederskap, politikk og identitet.

Sam, D.L., Dr.psychol. Acculturation of young immigrants in Norway: A psychological and socio-cultural adaptation.

Bjaalid, I.-K., Dr.philos. Component processes in word recognition.

Martinsen, Ø., Dr.philos. Cognitive style and Insight.

Nordby, H., Dr.philos. Processing of auditory deviant events: Mismatch negativity of event-related brain potentials.

Raaheim, A., Dr.philos. Health perception and health behaviour, theoretical considerations, empirical studies, and practical implications.

Seltzer, W.J., Dr.philos. Studies of Psychocultural Approach to Families in Therapy. 
Brun, W., Dr.philos. Subjective conceptions of uncertainty and risk.

1995-1996 Anderssen, N., Dr.psychol. Physical activity of young people in a health perspective: Stability, change and social influences.

Bjørkly, S., Dr.psychol. Diagnosis and prediction of Intra-institutional Aggressive Behaviour in Psychotic patients.

Aas, H.N., Dr.psychol. Alcohol Expectancies and Socialization: Adolescents learning to drink.

Sandal, G.M., Dr.psychol. Coping in Extreme Environments: The Role of Personality.

Strumse, E., Dr.philos. The psychology of aesthetics: explaining visual preferences for agrarian landscapes in Western Norway.

Hestad, K., Dr.philos. Neuropsychological deficits in HIV-1 infection.

1996-1997 Lugoe, L.W., Dr.philos. Prediction of Tanzanian Students' HIV Risk and Preventive Behaviours.

Sandvik, B.G., Dr.philos. Fra distrktsjordmor til institusjonsjordmor.

Fremveksten av en profesjon og en profesjonsutdanning.

Lie, G.T., Dr.psychol. The Disease that Dares Not Speak its Name: Studies on Factors of Importance for Coping with HIV/AIDS in Northern Tanzania.

Øygard, L., Dr.philos. Health behaviours among young adults. A psychological and sociological approach.

Stormark, K.M., Dr.psychol.

Emotional Modulation of Selective Attention: Experimental and Clinical Evidence.

Einarsen, S., Dr.psychol. Bullying and harassment at work: epidemiological and psychosocial aspects.

Knivsberg, A,-M.,

Behavioural abnormalities and childhood Dr.philos. psychopathology: Urinary peptide patterns as a potential tool in diagnosis and remediation.

Eide, A., Dr.philos. Adolescent drug use in Zimbabwe. Cultural orientation in a global-local perspective and use of psychoactive substance among secondary school students. 
Sørensen, M., Dr.philos. The psychology of initiating and maintaining exercise and diet behaviour.

Skjæveland, O., $\quad$ Relationships between spatial-physical neighborhood

Dr.psychol.

Zewdie, T., Dr.philos

Wilhelmsen, B.U., Dr.philos.

1997-1998 Manger, T., Dr.philos. attributes and social relations among neighbors.

Mother-child relational patterns in Ethiopia. Issues of developmental theories and intervention programs.

Development and evaluation of two educational programmes designed to prevent alcohol use among adolescents.

Gender differences in mathematical achievement among Norwegian elementary school students.

Lindstrøm, T.C., Dr.philos. “Good Grief”: Adapting to Bereavement.

Skogstad, A., Dr.philos. Effects of leadership behaviour on job satisfaction, health and efficiency.

Haldorsen, E.M.H., Dr.psychol.

Besemer, S.P., Dr.philos. Creative Product Analysis: The Search for a Valid Model for Understanding Creativity in Products.

1998-1999 Winje, D., Dr.psychol. Psychological adjustment after severe trauma. A longitudinal study of adults' and children's posttraumatic reactions and coping after the bus accident in Måbødalen, Norway, 1988.

Vosburg, S.K., Dr.philos. The effects of mood on creative problem solving.

Eriksen, H.R., Dr.philos. Stress and coping: Does it really matter for subjective health complaints?

Jakobsen, R., Dr.psychol. Empiriske studier av kunnskap og holdninger om hiv/aids og den normative seksualle utvikling $\mathrm{i}$ ungdomsårene.

Mikkelsen, A., Dr.philos. Effects of learning opportunities and learning climate on occupational health.

Samdal, O., Dr.philos. The school environmental as a risk or resource for students' health-related behaviours and subjective well-being.

Friestad, C., Dr.philos. Social psychological approaches to smoking.

Ekeland, T.-J., Dr.philos. Meining som medisin. Ein analyse av 
placebofenomenet og implikasjoner for terapi og terapeutiske teoriar.

1999-2000 Saban, S., Dr.psychol. Brain Asymmetry and Attention: Classical Conditioning Experiments.

Carlsten, C.T., Dr.philos. God lesing - God læring. En aksjonsrettet studie av undervisning i fagtekstlesing.

Dundas, I., Dr.psychol. Functional and dysfunctional closeness. Family interaction and children's adjustment.

Engen, L., Dr.philos. Kartleggin av leseferdighet på småskoletrinnet og vurdering av faktorer som kan være av betydning for optimal leseutvikling.

Hovland, O.J., Dr.philos. Transforming a self-preserving " alarm" reaction into a self-defeating emotional response: Toward an integrative approach to anxiety as a human phenomenon.

Lillejord, S., Dr.philos. Handlingsrasjonalitet og spesialundervisning. En analyse av aktørperspektiver.

Sandell, O., Dr.philos. Den varme kunnskapen.

Oftedal, M.P., Dr.philos. Diagnostisering av ordavkodingsvansker: En prosessanalytisk tilnærmingsmåte.

2000-2001 Sandbak, T., Dr.psychol. Alcohol Consumption and preference in the Rat: The Significance of Individual Differences and Relationships to Stress Pathology.

Eid, J., Dr.psychol. $\quad$ Early Predictors of PTSD Symptom reporting: The significance of contextual and individual factors.

Skinstad, A.H., Dr.philos. Substance Dependence and Borderline Personality Disorders.

Binder, P.-E., Dr.psychol. Individet og den meningsbærende andre. En teoretisk undersøkelse av de mellommenneskelige forutsetningene for psykisk liv og utvikling med utgangspunkt i Donald Winnicotts teori.

Roald, I.K., Dr.philos. Building of Concepts. A Study of Physics concepts of Norwegian Deaf students.

2001-2002 Fekadu, Z.W., Dr.philos. Predicting contraceptive use and intention among a sample of adolescent girls. An application of the theory of planned behaviour in Ethiopian context. 
Melesse, F., Dr.philos. The more intelligent and sensitive child (MISC) mediational intervention in an Ethiopian context: An evaluation study.

Råheim, M., Dr.philos. Kvinners kroppserfsaring og livssammenheng. En fenomenologisk - hermeneutisk studie av friske kvinner og kvinner med kroniske muskelsmerter.

Engelsen, B.K., Measurement of the eating problem construct.

Dr.psychol.

Lau, B., Dr.philos.

Weight and Eating Concerns in Adolescence.

Ihlebæk, C., Dr.philos. Epidemiological Studies of Subjective Health Complaints.

Rosen, G.O.R., Dr.philos. The phantom limb experience. Models for understanding and treatment of pain with hypnosis.

Høines, M.J., Dr.philos. Fleksible språkrom. Matematikklæring som tekstutvikling.

Anthun, R.A., Dr.philos. School psychology service quality. Consumer appraisal, quality dimensions, and collaborative improvement potential.

Pallesen, S., Dr.psychol. Insomnia in the elderly. Epidemiology, psychological characteristics and treatment.

Midthassel, U.V., Dr.philos.

Teacher involvement in school development activity. A study of teachers in Norwegian compulsory schools.

Kallestad, J.H., Dr.philos. Teachers, schools and implementation of the Olweus Bullying prevention program.

2002-2003 Ofte, S.H., Dr.psychol. Right-left discrimination in adults and children.

Netland, M., Dr.psychol. Exposure to political violence. The need to estimate our estimations.

Diseth, A., Dr.psychol. Approaches to learning: Validity and prediction of academic performance.

Bjuland, R., Dr.philos. Problem solving in geometry. Reasoning processes of student teachers working in small groups: A dialogical approach.

Arefjord, K., Dr.psychol. After the myocardial infarction - the wives' view. Short- and long-term adjustment in wives of myocardial infarction patients. 